NBSIR 78-1432

\title{
Automation of the lon Energetics Data Center
}

R. Thompson*

W. Webb

H. M. Rosenstock

Institute for Materials Research

National Bureau of Standards

Washington, D.C. 20234

- Office of Standard Reference Data

National Bureau of Standards

Washington, D.C. 20234

December 1977

Final

This work was supported in part by the

National Institute of General Medical Sciences

National Institutes of Health

Bethesda, Maryland 20014 



\section{AUTOMATION OF THE ION ENERGETICS DATA CENTER}

R. Thompson*

W. Webb

H. M. Rosenstock

Institute for Materials Research

National Bureau of Standards

Washington, D.C. 20234

" Office of Standard Reference Data

National Bureau of Standards

Washington, D.C. 20234

December 1977

Final

This work was supported in part by the National institute of General Medical Sciences

National Institutes of Health

Bethesda, Maryland 20014

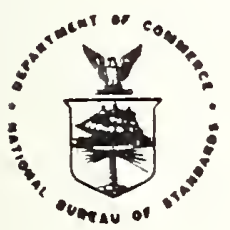

U.S. DEPARTMENT OF COMMERCE, Juanita M. Kreps, Secretary

Dr. Sidney Harman, Under Secretary

Jordan J. Baruch. Assistant Secretary for Scjence and Technology

NATIONAL BUREAU OF STANDARDS. Ernest Ambler, Acting Director 


$$
-
$$


Abstract

The Ion Energetics Data Center is engaged in the compilation, evaluation and dissemination of experimental information on gaseous ion energetics. Outputs include bibliographic and tabular information on ionization potentials, appearance potentials, electron affinities and heats of formation of gaseous positive and negative ions. The operation of the data center is discussed. This operation has recently been automated by the development of a set of computer programs, called IONPACK, which minimize the manual effort required for the numerous file manipulations and editing steps necessary to produce the data center output. The functions of the programs are outlined and the associated operating procedures are described in detail. Full documentation of the programs is presented in a separate report. 
- 
1. THE ION ENERGETICS DATA CENTER . . . . . . . . . . . . . . 3

1.1 Introduction. . . . . . . . . . . . . . . . . 3

1.2 The Subject Matter - Ion Energetics . . . . . . . . . . 3

1.3 Objectives of the Automation Effort . . . . . . . . . 6

1.4 Activities. . . . . . . . . . . . . . . . 6

2. THE INFORMATION. . . . . . . . . . . . . . . . . . . 7

2.1 The Abstract. . . . . . . . . . . . . . 7

2.2 The Basic Unit of Information . . . . . . . . . . . . 9

2.2 .1 Ion . . . . . . . . . . . . . . 9

2.2.2 Reactant. . . . . . . . . . . . . . 9

2.2.3 Other Products. . . . . . . . . . . . . 12

2.2.4 AP or IP. . . . . . . . . . . . . . . 12

2.2.5 Method. . ..................12

2.2.6 Reference .....................13

2.2.7 Associated Comments . . . . . . . . . . . . 13

3. DOCUMENT CONTROL AND STATUS FILES. . . . . . . . . . . . . . 17

4. INTERIM OUTPUT FILES AND ORDERED INFORMATION . . . . . . . . . . 19

4.1 Output Files. . . . . . . . . . . . . . . . . . . . . .

4.2 Ordering Principles . . . . . . . . . . . . . . 19

4.2.1 Bibliography and Author Index . . . . . . . . . 19

4.2.2 Ion Data.................... . . . . . . .

A. Atomic Composition, Complexity and Charge . . . .21

B. Reactant Species. . . . . . . . . . . . .21

C. Method. . . . . . . . . . . . 30

D. Measured Value. . . . . . . . . . . . 31

E. Output.................. . . . . . . 
5. PRESENT STATUS OF THE AUTOMATED SYSTEM . . . . . . . . . . . . . . . . . 33

6. KEYBOARDING THE ABSTRACT . . . . . . . . . . . . . . . . . 35

6.1 Format of the Abstract. . . . . . . . . . . . . . . 35

7. CONVERTING ATS KEYBOARDING TO GPSDC FILE . . . . . . . . . . . . 37

7.1 Requesting an ATS Archival Tape . . . . . . . . . . . . . 37

7.2 Converting the Archival Tape to GPSDC .............. . . . . . 77

8. Generating THE REQUiRed OUTPUTS. . . . . . . . . . . . . . . . . 43

8.1 Printing the $5 \times 8$ Cards. . . . . . . . . . . . . . . .45

8.2 Sorting the Raw Ion Data File... . . . . . . . . . . . .45

8.3 Printing the Raw Ion Data File. . . . . . . . . . . . .53

8.4 Program WREFS . . . . . . . . . . . . . . . . . . 60

8.5 Sorting the Author Index Entries. . . . . . . . . . . . . 60

9. ACKNOWLEDGMENTS. . . . . . . . . . . . . . . . . . . . . . . . . .

10. LIST OF FIGURES. . . . . . . . . . . . . . . . . . 66

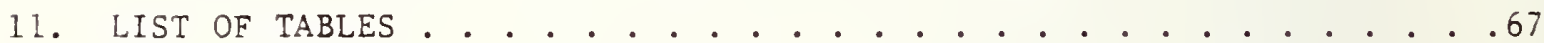

12. REFERENCES . . . . . . . . . . . . . . . . . . . . . . . . . . . .

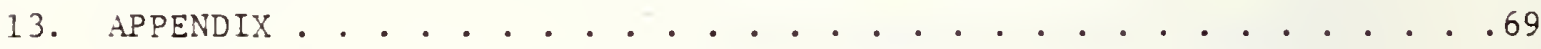


1. THE ION ENERGETICS DATA CENTER

\subsection{Introduction}

The Ion Energetics Data Center has recently carried out a major automation of its scientific data processing activities. The present report is a detailed description of the newly automated data center activity, prepared in order to provide:

a. an acccurate record of the objectives, mechanics, and procedures of the data center for tts own staff.

b. a well defined point of departure for future additions and modifications of the automated system.

c. a detailed example of data center automation which may be of use to other data centers.

The report is divided into three parts describing the technical subject matter and objectives of the data center (Section 1), the structure and function of the automated information processing system (Sections 2 to 5), and, lastly, a detailed operating manual for the technical information specialist responsible for the effective implementation of the various automated information processing steps comprising the system.

1.2 The Subject Matter - Ion Energetics

For purposes of the present report the term ion energetics includes most experimental data which can be interpreted or extrapolated to yield standard heats of formation of gaseous positive ions. Examples of such data include measurements of ionization and appearance potentials by a variety of techniques including vacuum ultraviolet spectroscopy, 
photolonization, electron spectroscopy, electron impact, surface ionization, empirical relationships between charge transfer spectra and ionization potentials. These techniques differ greatly in their accuracy depending both on the degree of care and refinement of their experimental realization and, frequently, also on the molecular structure and complexity of the system studied. Details of the various techniques, their accuracies and associated problems of data interpretation are described in a recent critical review. ${ }^{1}$

In 1969 and 1977 the Data Center compiled, evaluated, organized and disseminated this type of ion energetics data in the form of published data compilations 2,3 . A typical page of the 1977 compilation is shown in figure 1. All measurement information pertinent to one ion is organized in a form showing the nature of the ionic species, its electronic state where known, the molecular system studied (reactant), other products formed in the ionization process (where known), the experimental datum and its quoted accuracy or precision, an acronym describing the experimental technique (see Table 4, page 31), the heat of formation derived from the measurement datum for those measurements which are judged most reliable, and the reference number or numbers. The latter are random access ion numbers of the individual articles in the data center document files. The last line of the figure shows a name for the compound $\left(\mathrm{CH}_{2}\right)_{2} \mathrm{O}$ for which a one-line formula representation is not sufficient to uniquely indicate its chemical composition, namely the ring compound 1,2-epoxyethane. In addition to this main table, the compilation also contains an ion index bibliography, author index, and diverse auxiliary information. 


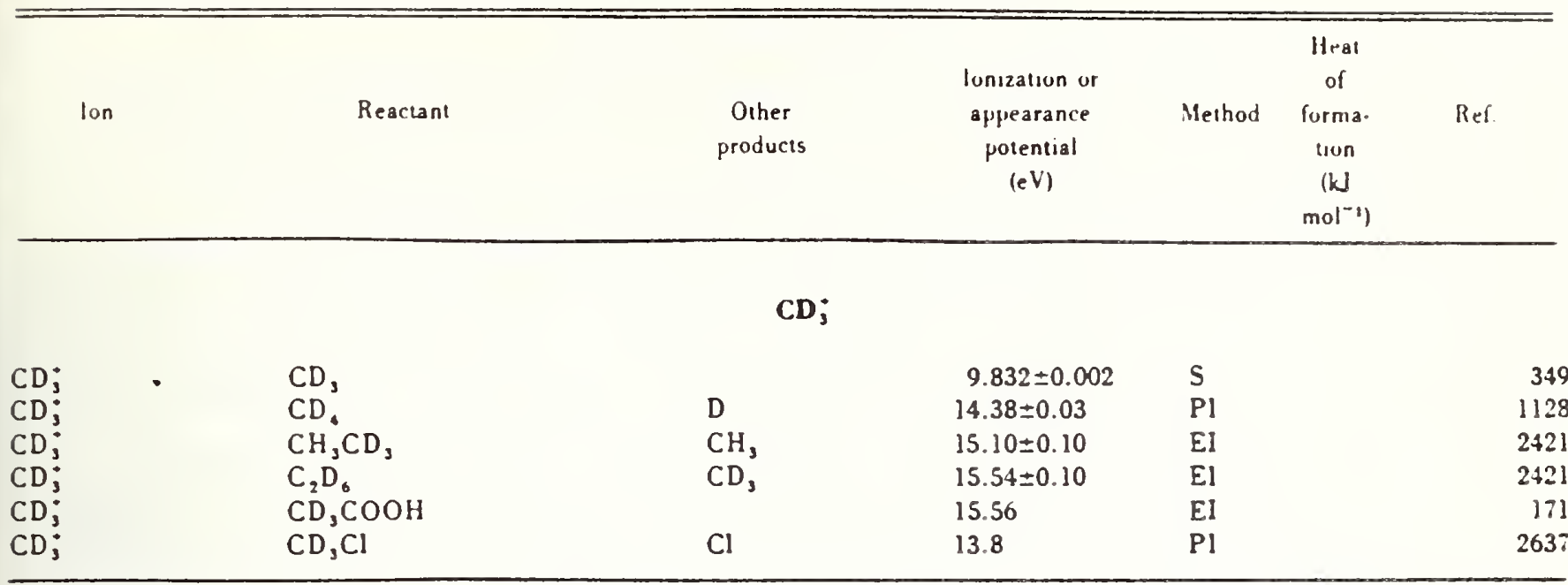

$$
\begin{array}{ll}
\mathrm{CH}_{4}^{*}\left({ }^{2} \mathrm{~B}_{2}\right) & \Delta \mathrm{H}_{10}^{\circ} \leqslant 1150 \mathrm{~kJ} \mathrm{~mol}^{-1}\left(275 \mathrm{kcal} \mathrm{mol}^{-1}\right) \\
\left.\mathrm{CH}_{4}^{*}{ }^{2} \mathrm{~A}_{1}\right) & \Delta \mathrm{H}_{10}^{\circ}=2094 \mathrm{~kJ} \mathrm{~mol}^{-1}\left(500 \mathrm{kcal} \mathrm{mol}^{-1}\right)
\end{array}
$$

\begin{tabular}{|c|c|c|c|c|c|}
\hline $\mathrm{CH}{ }_{4}\left({ }^{2} \mathrm{~B}_{2}\right)$ & $\mathrm{CH}_{4}$ & $\leqslant 12.615 \pm 0.010$ & $\mathrm{Pl}$ & $\leqslant 1150$ & \\
\hline $\mathrm{CH}\left({ }_{4}^{2} \mathrm{~B}_{2}\right)$ & $\mathrm{CH}_{4}$ & $12.704 \pm 0.008$ & $\mathrm{PI}$ & & \\
\hline $\mathrm{CH}\left({ }^{2} \mathrm{~B}_{2}\right)$ & $\mathrm{CH}_{4}$ & $12.71=0.02$ & Pl & & \\
\hline $\mathrm{CH}\left({ }^{2} \mathrm{~B}_{2}\right)$ & $\mathrm{CH}_{4}$ & $12.55 \pm 0.05$ & PI & & \\
\hline $\mathrm{CH}\left({ }^{2} \mathrm{~B}_{2}\right)$ & $\mathrm{CH}_{4}$ & $12.75 \pm 0.05$ & RPI & & $285 \%$ \\
\hline $\mathrm{CH} \cdot\left({ }^{2} \mathrm{~B}_{2}\right)$ & $\mathrm{CH}_{4}$ & 12.70 & PE & & \\
\hline $\mathrm{CH}\left({ }^{2} \mathrm{~B}_{2}\right)$ & $\mathrm{CH}_{4}$ & 12.75 & $P E$ & & \\
\hline $\mathrm{CH}\left({ }^{2}{ }^{2} \mathrm{~B}_{2}\right)$ & $\mathrm{CH}_{4}$ & 12.78 & PE & & \\
\hline $\mathrm{CH}_{4}\left({ }^{2} \mathrm{~B}_{2}\right)$ & $\mathrm{CH}_{4}$ & 12.9 & PEN & & \\
\hline $\mathrm{CH}\left({ }^{2}{ }^{2} \mathrm{~B}_{2}\right)$ & $\mathrm{CH}_{4}$ & $\leqslant 12.70^{\circ}$ & EM & & \\
\hline $\mathrm{CH}_{4}\left({ }^{2} \mathrm{~B}_{2}\right)$ & $\mathrm{CH}$. & $13.00 \pm 0.02$ & RPD & & \\
\hline $\mathrm{CH}_{4}\left({ }^{2} \mathrm{~B}_{2}\right)$ & $\mathrm{CH}_{4}$ & $12.99 \pm 0.05$ & RPD & & \\
\hline
\end{tabular}

The ion ground state has a large Jahn-Teller distorion, see for example R. N. Dixon, Mol. Phys. 20 , 113 (1971), F. A. Grimm and J. Godoy, Chem. Phys. Letters 6, 336 (1970) and refs. 3092, $3116,3119$. Consequently the onset is not sharp and the adiabatic value may be lower. Several PE studies (refs. 2803, 3092, 3119) have resolved vibrational structure near onset with a separation of $-1200 \mathrm{~cm}^{-1}$ $(0.15 \mathrm{eV})$. This is just the difference between the Pl threshold value given by Brehm, ref. 2013, and those determined by Nicholson, ref. 1253, and Dibeler et al., ref. 1128.

Sec also - S: $\quad 138$

Pl: $\quad 182,230,331,416,2605,3115,3132$

PE: $\quad 1130,2801,2829,2843,3072,3119,3132$

PEN: 2467

El: $\quad 289,1072,1129,2136,2154,2414,2535,2575,3435$

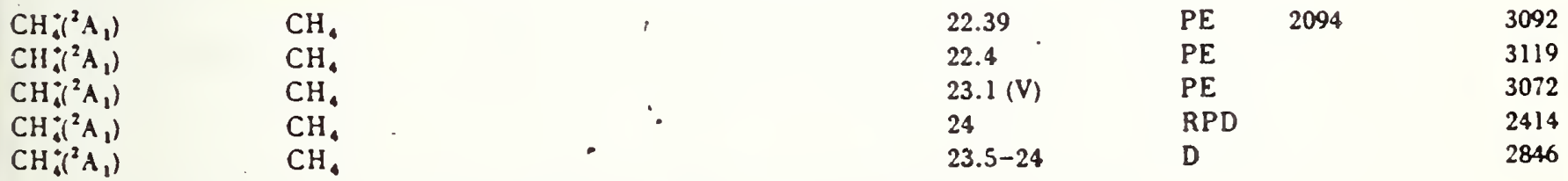

Earlier electron impact work (refs. 289, 1072) gave values around $19.4 \mathrm{eV}$. These are due to

\begin{tabular}{|c|c|c|c|c|c|}
\hline $\begin{array}{l}\mathrm{CH}: \\
\mathrm{CH}:\end{array}$ & $\begin{array}{l}\mathrm{C}, \mathrm{H}_{0} \\
(\mathrm{CH})_{2} \mathrm{O} \\
(1,2-\text { Epoxyethane })\end{array}$ & $\mathrm{CO}$ & $\begin{array}{l}14.7 \pm 0.5 \\
12.3 \pm 0.2\end{array}$ & $\begin{array}{l}\text { EI } \\
\text { EI }\end{array}$ & $\begin{array}{r}2542 \\
50\end{array}$ \\
\hline
\end{tabular}
autoionization or collision processes, see refs. 2414, 2575, 2846.

Figure 1. A typical page of the 1977 compilation. 
1.3 Objectives of the Automation Effort

The purpose of the automation effort is to automate to the maximum feasible extent the many routine data management activities associated with the creation, updating, and editing of the many ordered files, all of which are ultimately derivable from the abstracted document. The automated data management system described here is designed to provide a set of computer files which are suited for computer typesetting via the Government Printing Office Linatron machine. Finally, the system is designed to allow the extraction of chemically meaningful subsets of information such as topical bibliographies and information on specific ions or classes of ions. Ultimately, it is hoped to develop a data base that can be interrogated and output via a remote terminal and at the same time to provide ordered, edited material suitable for typesetting. At present, the latter objective has dominated our planning.

It is planned to issue from time to time supplements to the existing compilation which lists the more recent unevaluated measurements and associated references in ordered form. Then, when the unevaluated data file is brought up-to-date, it is planned to combine the material with the 1977 data compilation and to produce a revised, updated compilation.

\subsection{Activities}

The activities leading to these objectives can be divided into three categories.

a. Searching, abstracting and encoding the abstracted information.

b. Processing of the encoded information to yield various desired files and outputs. We note here explicitly that part of the 
processing involves, stripping, sorting and ordering the information on the abstracts.

c. Merging the information with the existing compilation, evaluating and editing the new body of information and producing a new typeset hard copy.

Needless to say, the objective of producing a new compilation

which is merged with the existing one imposes the necessity of generating information files which are as similar as posstble in format and ordering philosophy to the existing compilation.

\section{THE INFORMATION}

\subsection{The Abstract}

The abstract consists of all ion data from a given document with associated citation 1nformation. The data are discussed in detail below. Th1s is the fundamental document from which all subsequent files and outputs are derived. Thus it is extremely important to check the accuracy of abstracting and encoding.

A form as filled out by the abstractor is shown in figure 2. The ID number or accession number of the reprint is added to the form and the reprint by the scientific data clerk at the time for encoding. The computer program will associate it with each ion datum.

The author, title and reference are checked and modified by the scientific data clerk for consistency of format and abbreviation.

Since almost all papers employ only one method, the abstractor clrcles the appropriate method, and the scientific data clerk will associate it with each ion datum as it is encoded. If a paper cites 
$\frac{u}{a}=$

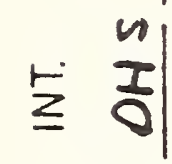

15

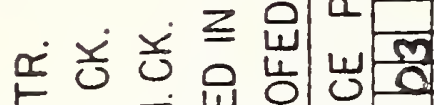

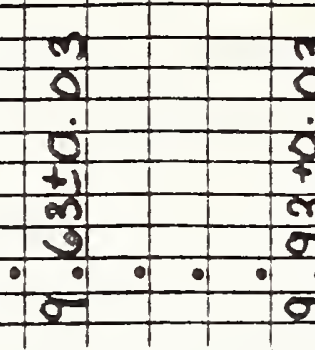

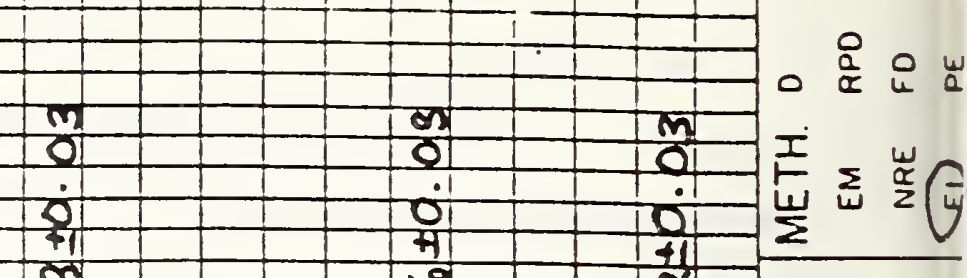

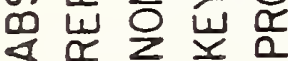

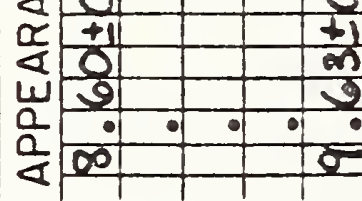

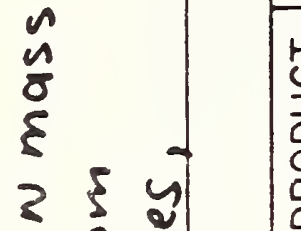

$\varepsilon \leq \frac{2}{2}$

5

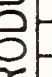

$44=$

右

(I)

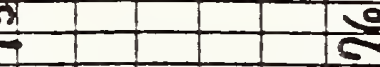

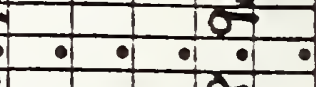

$\Sigma$

$w \frac{t}{t}$

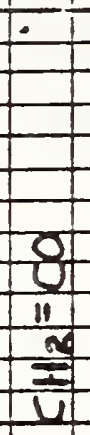

$-\infty$

$\infty$

후워

I-

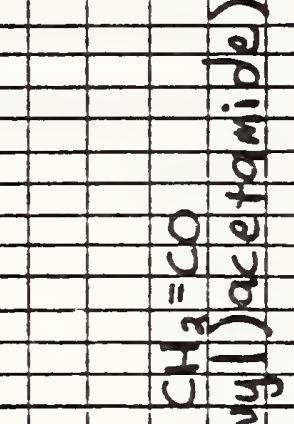

ร) 4 의

मे ठ당

Eิ

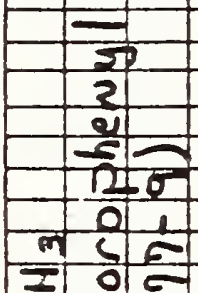

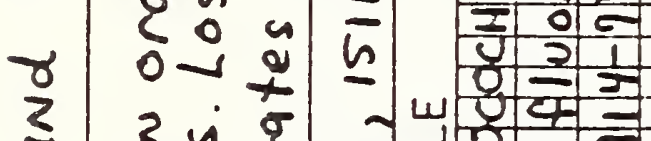

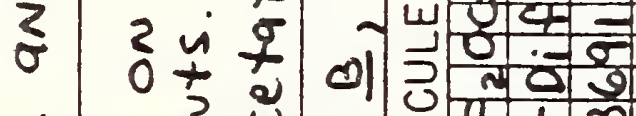

वे « ?

$+\varepsilon \delta$ j

उ क ज

ช

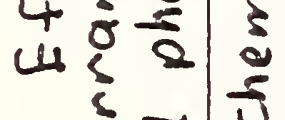

3 1

व

ஸ

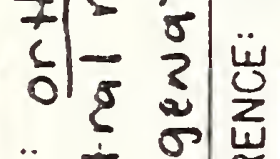

岂 す

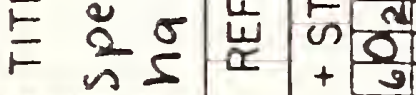

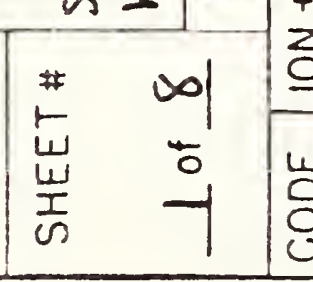

$+\frac{9}{2}$

क्रे

In

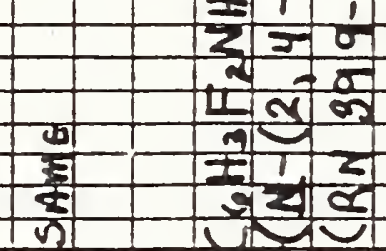

-

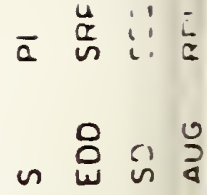

क ริ n ?

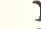


two or more methods, provision is made in the other method column for entering the other method acronym.

At the left hand margin of the form, five columns are set aside for flagging symbols which are entered by the scientific data clerk at the time of encoding. The nature and purpose of the flagging is described in a later section.

After encoding, the written abstract form is attached to the reprint and filed. The encoded form of the abstract is shown in figure 3 .

Detailed guidelines for abstracting are given in a separate document. 4

2.2 The Basic Unit of Information

The basic unit of information of the data base is the numerical value of a measurement relating to a particular ionic species and its associated detail and documentation. We will call this an ion datum. It consists in all cases of the following items of information arranged horizontally ION REACTANT OTHER PRODUCT AP or IP METHOD REF
$(\mathrm{eV})$

and a number of parenthetical comments.

\subsubsection{Ion - The ion is always represented by an empirical}

molecular formula and a charge. In addition, where pertinent, the electronic state of the ion is also given in parentheses.

Examples: $\mathrm{CH}_{3}^{+}, \mathrm{Ar}^{+4}, \mathrm{Ne}^{+}\left({ }^{2} \mathrm{P}_{3 / 2}\right), \mathrm{N}_{2} \mathrm{O}^{+}\left(\mathrm{X}^{2} \pi_{1 / 2}\right), \mathrm{N}_{2}^{+3}, \mathrm{C}_{3} \mathrm{H}_{6}^{+}$

2.2.2 Reactant - This is the species on which the measurement is made. It consists in most, but not all, instances of stable gas phase molecules in their ground electronic state. Occasionally this species may consist 


\subsubsection{Other Product - In some processes leading to ion} energetic information, the ion of interest is formed by fragmentation of the subject molecule, and is thus accompanied by another atomic, ionic or polyatomic fragment species. Such processes include

$$
\begin{aligned}
& \mathrm{C}_{2} \mathrm{H}_{6}+\mathrm{e} \rightarrow \mathrm{C}_{2} \mathrm{H}_{5}^{+}+\mathrm{H}+2 \mathrm{e} \\
& \mathrm{CH}_{3} \mathrm{Cl}+\mathrm{hu} \rightarrow \mathrm{CH}_{3}^{+}+\mathrm{Cl}^{-} \\
& \mathrm{C}_{6} \mathrm{H}_{5} \mathrm{C}_{2} \mathrm{H}_{5}+\mathrm{e} \rightarrow \mathrm{C}_{7} \mathrm{H}_{7}^{+}+\mathrm{CH}_{3}+2 \mathrm{e}
\end{aligned}
$$

\section{(Ethylbenzene)}

$$
\left.\mathrm{N}_{2} \mathrm{O}+\mathrm{hv} \rightarrow \mathrm{NO}^{+}+\mathrm{N}^{4} \mathrm{~S}_{\mathrm{O}}\right)+\mathrm{e}
$$

Al1 products except electrons are tabulated under other products. In some instances the other product may consist of more than one fragment.

$$
\mathrm{B}_{5} \mathrm{H}_{\mathrm{II}}^{\cdot}+\mathrm{e} \rightarrow \mathrm{B}_{5} \mathrm{H}_{7}^{+}+2 \mathrm{H}_{2}+2 \mathrm{e}
$$

2.2.4 AP or IP - This is the measured quantity, the appearance potential (AP) or ionization potential (IP). It is always given in electron volts. The probable error of the quantity is always the one given in the source paper, where stated. Occasionally the AP or IP is given as an upper bound, $\leq 10.2 \mathrm{eV}$ or a range $15.4225-15.4255 \mathrm{eV}$ or an approximation ". $10.72 \mathrm{eV}$.

\subsubsection{Method - The ion energetics measurements are carried} out by a variety of techniques. They are denoted by two-or three-letter acronyms. The acronyms and names of the methods are given in the accompanying 1ist. The methods are ordered according to generally decreasing reliability, although in some particular instances a 
measurement by a "high ranking" method may give a less precise answer than a measurement on the same system by a "lower ranking" method. In general a given paper may give information on one or more ions based on measurements of one or more molecules. But almost always a given paper reports on measurements using only one method. Some of the "methods" are rather indirect, such as use of the Born-Haber cycle or application of semi-empirical relations between charge transfer spectra in solution and gas phase ionization potentials. The methods are described and discussed in detail in reference 1.

$$
\text { 2.2.6 Reference - This ties the ion datum to the journal }
$$

reference and document (reprint) file. It is simply a four-digit accession number.

\subsubsection{Associated Comments - There are several purposes for} the comments on an ion datum as indicated above. For cyclic compounds a one-line formula representation is inadequate to identify the compound. Therefore it has been decided to provide the name for all such compounds. We have arbitrarily chosen to adopt the Chemical Abstract nomenclature system. However, this nomenclature system is not static, new names are added and old names are ocasionally changed. Thus we have decided to give the CAS Reglstry Number as well, both for cyclic and acyclic compounds. The Registry Number, although arbitrary, is not subject to change and offers the possibility of entering into other nomenclature and structure representation systems such as the Wisswesser system and schemes for generating formulas and structures by computer techniques. Thus, for acyclic systems we always have the CAS Registry Number and for cyclic systems the CA Name and CAS Registry Number as comments. Besides these two, there are eighteen other comments which given additional information 
Table 1. List of Comments and Coding Acronyms (continued)

RC Mean value of Renner components
Name used by author:
OP The other product (s) is (are)
MT, NI, TR ure used principally as an aid in establishing the validity
of other product statement. They may be discarded (or
not) in the final revised edition. Use as many as
appropriate.
One cannot simply give sum of kinetic energies of two
successive metastables.
The reason is simply that one looks for evidence that one
reaction step occurred.
Used where limits are impossible to assign to spin-orbit
components.
Used where there are several Crs values.
Used for transient species produced in ion source by
electron impact.
$* * * * * * * *$ Used ion pair processes.


3. DOCUMENT CONTROL AND STATUS FILES

In this section we discuss the logistics and file structure associated with the production of a correct archival tape of abstracted information. The general scheme is shown in figure $4 . \mathrm{P}_{1}, \mathrm{P}_{2}, \mathrm{P}_{3}, \mathrm{P}_{4}, \mathrm{P}_{5}, \mathrm{P}_{6}$, and $\mathrm{P}_{7}$ refer to computer programs described in section 5.

The literature search identifies articles which may contain information of interest. As the reprints are processed they are stored in an unabstracted reprint file and a document control card is typed and filed alphabetically by first author. This is an accessible reference file for documents on hand. After a batch of reprints have been abstracted, the abstracts are encoded on a Model 37 TTY, a printout of the encoded material is produced, proofed and, if necessary, corrected. The processed reprints and associated abstracts are stored in a separate file ordered by accession number. The corrected abstract tape is now processed to produce the following printed outputs: a printout of the abstracts in serial order. of accession number, a printed document control card with ID number and a series of separate cards, one for each ion datum. Additional outputs are discussed in the next section.

The printed document control card then is used to replace the typed card in the document control file, thus indicating which of the documents have been processed. Also if it is needed to refer to a document by conventional author and journal reference it and/or its abstract can be located in the ID ordered file or the printout of abstracts.

The ion datum cards are further sorted by hand according to molecule composition of the ion and generate a card file useful in locating processed information on a particular ion. 
4.1 Output Files

It was mentioned above that it is intended to prepare during the course of the work a series of raw data supplements for interim use by the user community prior to issuance of the revised compilation. The supplements will list in ordered form all measurements abstracted for the later calendar years, 1972,1973 etc. as the work progresses. They would be similar in format to the compilation, and will include bibliographies and author indexes. As these are issued it is intended to establish and maintain a set of cumulative files of this type which will ultimately be merged with the existing compilation.

In order to accomplish this it is necessary to separate the abstract information into certain component parts, generate a means of sorting the required parts, i.e. develop and attach a sort key, cumulate the processed batched into files holding the information for a year, sort the files into ordered files, format them and print them. This is shown schematically in figure 5 .

\subsection{Ordering Principles}

4.2.1 Bibliography and Author Index - The ordering principle for the bibliography is, of course, simply the accession number and the author index is alphabetical with the proviso that composite letters such as $\hat{A}, C, \hat{C}, \ddot{u}$, etc are treated as the corresponding ordinary letters, and hyphens and apostrophes are ignored in the alphabetical ordering process.

4.2.2 Ion Data - The ordering of the ion data is considerabiy more complex and is based on a hierarchy of four considerations: 


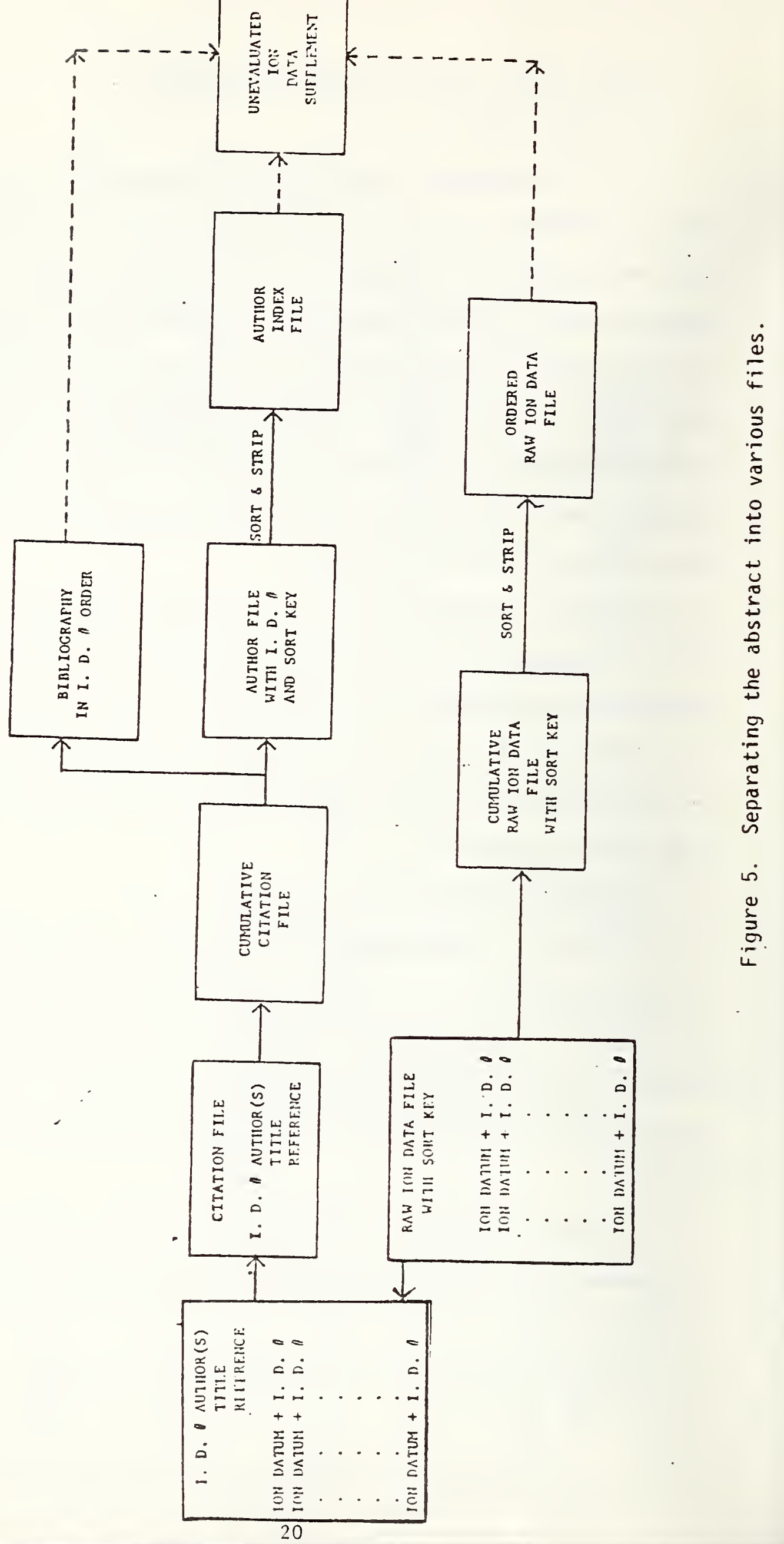


a. Atomic composition, complexity and charge of the ion and reactant species.

b. Chemical nature of the reactant species.

c. The measurement method.

d. The numerical value of the measurement.

A. Atomic Composition, Complexity and Charge The ordering principle for atomic composition

and complexity is expressed in the following way:

Species are grouped in increasing order according to the element of highest atomic number which they contain.

Within each group they are separated into subgroups consisting of species containing one chemical element, two chemical elements, three ... etc.

Within each subgroup those that contain the additional element(s) of lowest atomic number come first and are ordered by increasing number of atoms starting with the element of lowest atomic number.

All isotopes are ignored except for deuterium and tritium which are ordered according to increasing extent to which they substitute for hydrogen. Thus $\mathrm{CH}_{4}, \mathrm{CH}_{3} \mathrm{D}, \mathrm{CH}_{2} \mathrm{D}_{2}, \ldots \mathrm{CH}_{3} \mathrm{~T}$ and then $\mathrm{C}_{2} \mathrm{H}_{6}, \mathrm{C}_{2} \mathrm{H}_{5} \mathrm{D}, \mathrm{C}_{2} \mathrm{H}_{4} \mathrm{D}_{2} \ldots$ For a species of given atomic composition, the species are listed according to increasing positive charge.

\section{B. Reactant Species}

For a given ion the reactant species are again ordered according to the same principle of atomic composition, complexity and charge.

In addition, now, there is further ordering according to chemical structure. First, straight chain and branched chain compounds are 
placed before ring compounds, using the fact that all ring compounds have a name associated with them.

The straight-chain compounds of a given isomer are further ordered according to whether in the semi-structural formula representation there are any italicized prefixes indicative of different isomer structure. A complete list of these prefixes is given in Table 2 together with the decimal and octal equivalent numbers which represent them in the sort key (some are only applicable to ring substitution, see below). The

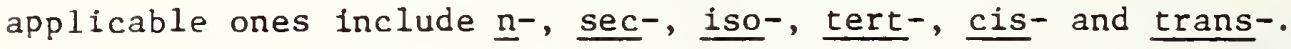

Those molecules with no prefixes at all will precede all molecules with prefixes. Finally, if necessary, the CA Registry Number is used for further sorting.

As for the ring compound isomers, they are ordered according to the compound name. Since the nomenclature is quite complex, containing isomer prefixes, numbers locating double bonds or atom connections, as well as italicized or greek letters, the following scheme is employed. a. Form the "proper name" by scanning the name and extracting the first upper case latin letter and all subsequent lower case latin letters.

b. Add to this string all isomer prefix symbols or phrases, numbers or greek letters in the order that they appear in the entire name. These symbols or phrases are identified by the fact that they are lower case italic followed by a dash (see Table 2, page 23).

$$
\text { c. Substitute for each of the letters phrases, or }
$$
numbers of the string, an assoclated numerical value and sort the resulting string of numbers. The decimal equivalent numerical values associated with each letter, phrase or number are given in Table 3 . 
Table 2. List of Isomer Prefixes

in order of sort preference

Decimal Octal
Equivalent

\begin{tabular}{|c|c|c|c|c|c|}
\hline o- & 17 & 021 & cyclo- & 55 & 067 \\
\hline$m-$ & 18 & 022 & bicyclo-\& dicyclo- & 60 & 074 \\
\hline $\mathrm{p}^{-}$ & 19 & 023 & tricyclo- & 65 & 101 \\
\hline$n-$ & 20 & 024 & spiro- & 70 & 106 \\
\hline sec- & 25 & 031 & $\underline{\text { syn- }}$ & 75 & 113 \\
\hline iso- & 30 & 036 & anti- & 80 & 118 \\
\hline tert- & 35 & 043 & endo- & 85 & 125 \\
\hline neo- & 40 & 050 & exo- & 90 & 132 \\
\hline cis- & 45 & 055 & qra- & 95 & 137 \\
\hline trans- & 50 & 062 & opqra- & 100 & 144 \\
\hline
\end{tabular}


Table 3. Numerical Equivalents of GPSDC Symbols, Isomer Prefixes, Methods and Chemical Element Symbols

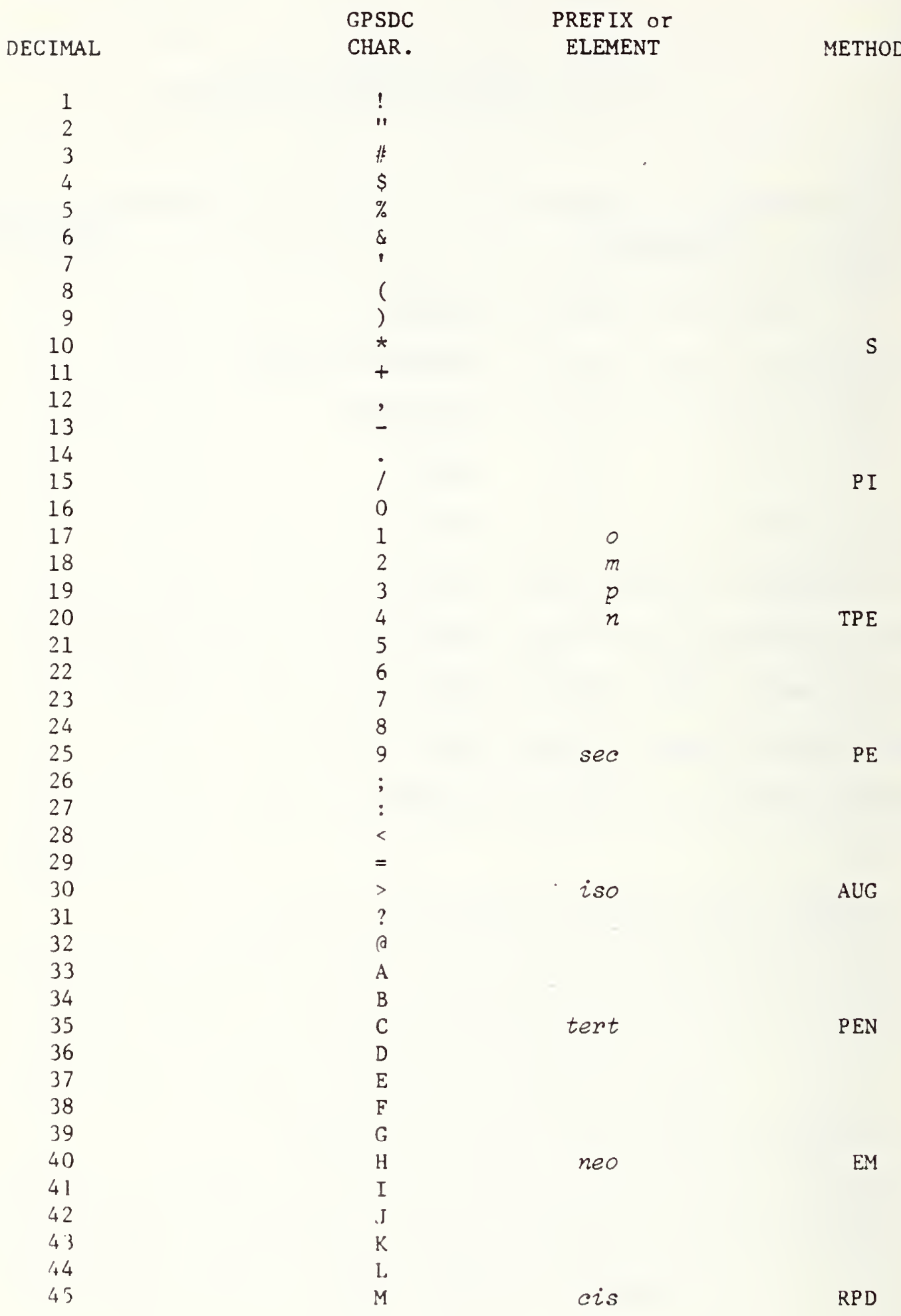


Table 3. Numerical Equivalents of GPSDC Symbols, Isomer Prefixes, Methods and Chemical Element Symbols (continued)

\begin{tabular}{|c|c|c|c|}
\hline DECIMAL & $\begin{array}{l}\text { GPSDC } \\
\text { CHAR. }\end{array}$ & $\begin{array}{l}\text { PREFIX or } \\
\text { ELEMENT }\end{array}$ & METHOD \\
\hline 46 & $\mathrm{~N}$ & & \\
\hline 47 & 0 & & \\
\hline 48 & $P$ & & \\
\hline 49 & $Q$ & & \\
\hline 50 & $\mathrm{R}$ & trans & EDD \\
\hline 51 & $S$ & & \\
\hline 52 & $T$ & & \\
\hline 53 & $\mathrm{U}$ & & \\
\hline 54 & V & & \\
\hline 55 & W & cyclo & NRE \\
\hline 56 & $\mathrm{X}$ & & \\
\hline 57 & $Y$ & & \\
\hline 58 & Z & & \\
\hline 59 & [ & & \\
\hline 60 & & bicyclo & $\mathrm{SRP}$ \\
\hline 61 & ] & & \\
\hline 62 & . & & \\
\hline 63 & - & & \\
\hline 64 & - & & \\
\hline 65 & a & tricyclo & ED \\
\hline 66 & $\mathrm{~b}$ & & \\
\hline 67 & c & & \\
\hline 68 & d & & \\
\hline 69 & e & & \\
\hline 70 & $\mathrm{f}$ & spiro & SD \\
\hline 71 & $\mathrm{~g}$ & & \\
\hline 72 & $\mathrm{~h}$ & & \\
\hline 73 & i & & \\
\hline 74 & j & & \\
\hline 75 & $\mathrm{k}$ & syn & SEQ \\
\hline 76 & 1 & & \\
\hline 77 & $\mathrm{~m}$ & & \\
\hline 78 & $\mathrm{n}$ & & \\
\hline 79 & o & & \\
\hline 80 & $\mathrm{p}$ & anti & $E I$ \\
\hline 81 & q & & \\
\hline 82 & $r$ & & \\
\hline 83 & s & & \\
\hline 84 & $t$ & & \\
\hline 85 & $\mathrm{u}$ & endo & - SI \\
\hline 86 & v & & \\
\hline 87 & $w$ & & \\
\hline 88 & $\mathrm{x}$ & & \\
\hline 89 & y & & \\
\hline 90 & $z$ & exo & CTS \\
\hline
\end{tabular}


Table 3. Numerical Equivalents of GPSDC Symbols, Isomer Prefixes, Methods and Chemical

Element Symbols (continued)

DECIMAL

GPSDC
CHAR.

PREFIX or

ELEMENT

METHOD

91

92

93

94

95

96

97

98

99

100

101

102

103

104

105

106

107

108

109

110

111

112

113

114

115

116

117

118

119

120

121

122

123

124

125

126

127

128

129

130

131

132

133

134

135

qra

BH

opqra

DM

$\mathrm{H}$

$\mathrm{He}$

Li

$\mathrm{Be}$

B

C

$\mathrm{N}$

0

F

$\mathrm{Ne}$

$\mathrm{Na}$

$\mathrm{Mg}$

A1

Si

$P$

$\mathrm{S}$

C1

Ar

$k$

Ca

Sc

$\mathrm{Tf}$

V

Cr

Mn

$\mathrm{Fe}$

Co

$\mathrm{NI}$

$\mathrm{Cu}$

$\mathrm{Zn}$

Ga

$\mathrm{Ge}$

As

$\mathrm{Se}$

$\mathrm{Br}$ 
Table 3. Numerical Equivalents of GPSDC Symbols, Isomer Prefixes, Methods and Chemical Element Symbols (continued)

\begin{tabular}{|c|c|c|c|}
\hline DECIMAL & $\begin{array}{l}\text { GPSDC } \\
\text { CHAR. }\end{array}$ & $\begin{array}{c}\text { PREFIX or } \\
\text { ELEMENT }\end{array}$ & METHOD \\
\hline 136 & $\Gamma$ & $\mathrm{Kr}$ & \\
\hline 137 & $\Delta$ & $\mathrm{Rb}$ & \\
\hline 138 & $\theta$ & $\mathrm{Sr}$ & \\
\hline 139 & $\Lambda$ & $Y$ & \\
\hline 140 & $\bar{\Xi}$ & $\mathrm{Zr}$ & \\
\hline 141 & $\bar{\pi}$ & $\mathrm{Nb}$ & \\
\hline 142 & $\Sigma$ & Mo & \\
\hline 143 & n & $\mathrm{Tc}$ & \\
\hline 144 & $\Phi$ & $\mathrm{Ru}$ & \\
\hline 145 & $\Psi$ & $\mathrm{Rh}$ & \\
\hline 146 & $\Omega$ & $\mathrm{Pd}$ & \\
\hline 147 & $\alpha$ & $\mathrm{Ag}$ & \\
\hline 148 & $\beta$ & $\mathrm{Cd}$ & \\
\hline 149 & $\gamma$ & In & \\
\hline 150 & $\delta$ & $\mathrm{Sn}$ & \\
\hline 151 & $\varepsilon$ & $\mathrm{Sb}$ & \\
\hline 152 & $\zeta$ & $\mathrm{Te}$ & \\
\hline 153 & $n$ & $I$ & \\
\hline 154 & $\theta$ & $\mathrm{Xe}$ & \\
\hline 155 & $\kappa$ & $\mathrm{Cs}$ & \\
\hline 156 & $\lambda$ & $\mathrm{Ba}$ & \\
\hline 157 & $\mu$ & $\mathrm{La}$ & \\
\hline 158 & u & $\mathrm{Ce}$ & \\
\hline 159 & $\xi$ & Pr & \\
\hline 160 & $\pi$ & $\mathrm{Nd}$ & \\
\hline 161 & p & $\mathrm{Pm}$ & \\
\hline 162 & $\sigma$ & $\mathrm{Sm}$ & \\
\hline 163 & $\tau$ & Eu & \\
\hline 164 & $\phi$ & $\mathrm{Gd}$ & \\
\hline 165 & $x$ & $\mathrm{~Tb}$ & \\
\hline 166 & $\psi$ & Dy & \\
\hline 167 & $\omega$ & Ho & \\
\hline 168 & & Er & \\
\hline 169 & & $\mathrm{Tm}$ & \\
\hline 170 & $\sim$ & $\mathrm{Yb}$ & \\
\hline 171 & & $\mathrm{Lu}$ & \\
\hline 172 & & Hf & \\
\hline 173 & $\approx$ & $\mathrm{Ta}$ & \\
\hline 174 & 2 & W & \\
\hline 175 & & $\mathrm{Re}$ & \\
\hline 176 & & Os & \\
\hline 177 & & Ir & \\
\hline 178 & & $\mathrm{Pt}$ & \\
\hline 179 & & $\mathrm{Au}$ & \\
\hline 180 & .. & $\mathrm{Hg}$ & \\
\hline
\end{tabular}


Table 3. Numerical Equivalents of GPSDC Symbols, Isomer Prefixes, Methods and Chemical Element Symbols (continued)

DECIMAL

GPSDC

PREFIX or

CHAR.

ELEMENT

METHOD

181

182

$\mathrm{T} 1$

$\mathrm{Pb}$

183

Bi

184

Po

185

At

186

$\mathrm{Rn}$

187

Fr

188

$\mathrm{Ra}$

189

Ac

190

191

192

193

194

195

196

197

198

199

200

201

202

203

204

205

206

207

208

209

210

211

212

213

214

215

216

217

218

219

220

221

222

223 
Table 3. Numerical Equivalents of CPSDC Symbois, Isomer Prefixes, Methods and Chemical

Element Symbols (continued)

DECIMAL

GPSDC

PREFIX or

CHAR .

ELEMENT

METHOD

224

225

226

227

228

229

230

231

232

233

234

235

236

237

238

239

240 
The procedure is illustrated with two examples below with the number string generated from the decimal.equivalent endo-5-Chlorobicyclo [2.2.1] hept-2-ene

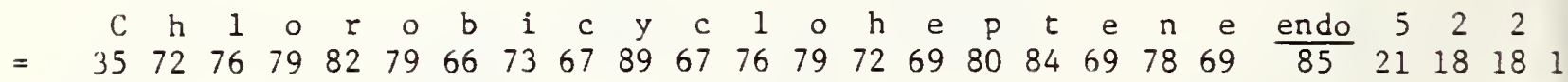
and anti-Tricyclo $[4.2 .0 .02,5]$ octa-3,7-diene

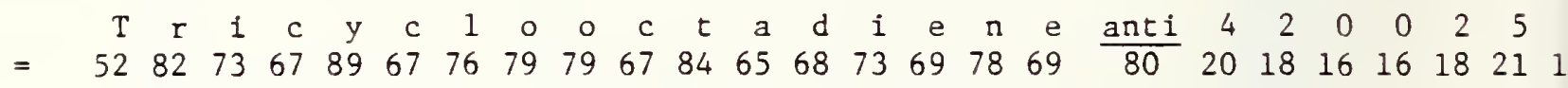

In the computer these numbers are represented by their octal equivalent.

The above procedure provides a crude but systematic way of ordering different isomer names. It was be useful for deciding unambiguously on the ordering if, as is typically the case, one has only a dozen or so isomers in a typical case. If on the other hand one had to derive an ordering principle applicable to several hundred isomers a totally different approach may be necessary, such as the use of the Wisswesser line notation.

\section{Method}

The next level of ordering the information, which is by now categorfzed by ion and specific reactant molecule, is to order according to measurement technique. The different methods are given in Table 4, and are shown in order of generally decreasing accuracy. This order is not universally valid but is a good first approximation. This ordering is adopted here.

\section{Measured Value}

Lastly, within these categories the information is ordered according to increasing numerical value of the measurement. The principal purpose of this ordering is to group together the information 
Table 3. Numerical Equivalents of GPSDC Symbols, Isomer Prefixes, Methods and Chemical Element Symbols (continued)

DECIMAL

GPSDC CHAR.
PREFIX or

ELEMENT
METHOD

224

225

226

227

228

229

230

231

232

233

234

235

236

237

238

239

240 
The procedure is illustrated with two examples below with the number string generated from the decimal equivalent endo-5-Chlorobicyclo [2.2.1] hept-2-ene

$\begin{array}{llllllllllllllllllllllllllll}c & h & 1 & \circ & r & o & b & i & c & y & c & l & \circ & h & e & p & t & e & n & e & \text { endo } & 5 & 2 & 2\end{array}$ $=\begin{array}{lllllllllllllllllllllllll}3572 & 76 & 79 & 82 & 79 & 66 & 73 & 67 & 89 & 67 & 76 & 79 & 72 & 69 & 80 & 84 & 69 & 78 & 69 & \frac{8}{85} & 21 & 18 & 18 & 1\end{array}$

and

anti-Tricyclo $[4.2 .0 .02,5]$ octa-3,7-diene

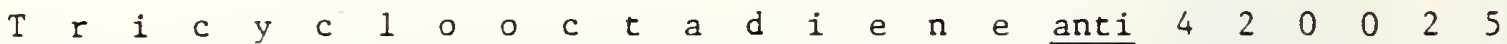
$=\begin{array}{llllllllllllllllllllllllll}52 & 82 & 73 & 67 & 89 & 67 & 76 & 79 & 79 & 67 & 84 & 65 & 68 & 73 & 69 & 78 & 69 & 80 & 20 & 18 & 16 & 16 & 18 & 21 & 1\end{array}$

In the computer these numbers are represented by their octal equivalent.

The above procedure provides a crude but systematic way of ordering different isomer names. It was be useful for deciding unambiguously on the ordering if, as is typically the case, one has only a dozen or so isomers in a typical case. If on the other hand one had to derive an ordering principle applicable to several hundred isomers a totally different approach may be necessary, such as the use of the Wisswesser line notation.

\section{Method}

The next level of ordering the information, which is by now categorized by ion and specific reactant molecule, is to order according to measurement technique. The different methods are given in Table 4, and are shown in order of generally decreasing accuracy. This order is not universally valid but is a good first approximation. This ordering is adopted here.

\section{Measured Value}

Lastly, within these categories the information is ordered according to increasing numerical value of the measurement. The principal purpose of this ordering is to group together the information 
Table 4. Techniques for Ion Energetics Measurements in Order of Sort Preference

\begin{tabular}{|c|c|c|c|}
\hline & & $\begin{array}{l}\text { Numerical } \\
\text { Decima } 1 \\
\end{array}$ & $\begin{array}{r}\text { Equivalent } \\
\text { Octal }\end{array}$ \\
\hline S & Spectroscopic & 10 & 012 \\
\hline PI & Photoionization & 15 & 017 \\
\hline TPE & $\begin{array}{l}\text { Threshold Photoelectron } \\
\text { Spectroscopy }\end{array}$ & 20 & 024 \\
\hline$P E$ & Photoelectron Spectroscopy & 25 & 031 \\
\hline AUG & Auger Electron Spectroscopy & 30 & 036 \\
\hline PEN & Penning Ionization & 35 & 044 \\
\hline EN & Electron Monochromator Studies & 40 & 050 \\
\hline RPD & Retarding Potential Difference & 45 & 055 \\
\hline EDD & Energy Distribution Difference & 50 & 062 \\
\hline NRE & $N^{t h}$ Root Extrapolation & 55 & 067 \\
\hline SRP & Square Root Plot & 60 & 074 \\
\hline FD & First Derivative & 65 & 101 \\
\hline SD & Second Derivative & 70 & 106 \\
\hline$S E Q$ & Sequential Ionization & 75 & 113 \\
\hline EI & Other Electron Impact & 80 & 118 \\
\hline SI & Surface Ionization & 85 & 125 \\
\hline cts & Charge Transfer Spectrum & 90 & 132 \\
\hline $\mathrm{BH}$ & Born-Haber Cycle & 95 & 137 \\
\hline $\mathrm{D}$ & Derived Value & 100 & 144 \\
\hline
\end{tabular}


on the various ionization potentials of a given molecule which is obtained by the photoelectron spectroscopy technique. Although the various electronic states of the ions have each a different spectroscopic designation, there is no ordering criterion based on the electronic state which is of wide enough validity for use here.

Comparing the more detailed ordering of ring compound isomers by compound name with the less detailed ordering of chain compound isomers, it is evident that the latter will not be totally ordered in some instances where there are no isomer prefixes and the isomers are distinguished by the one line scructural formula alone.

\section{Example: $\mathrm{CH}_{3} \mathrm{COCH}_{3}$ vs. $\mathrm{CH}_{3} \mathrm{CH}_{2} \mathrm{CHO}$.}

Here the ordering according to numerical value alone will be of some help if, as is often the case, the isomers have different IP or AP values.

In any event, the ordering will not always be perfect, and in the future it will be extremely useful to have a means of permitting the ordering of a group of ion datum lines.

\section{E. Output}

The interim output is obtained from the ordered raw ion data, bibliography and author index files in the form of computer printout which will be xeroxed or photocopied. In order to do this it will be necessary to strip the sort key from the material prior to printing out. The printout will be carried out on the NBS IBM 360 printer, using the extended character chain printer. This extended character chain comprises a set of characters appropriate to the presentation of scientific information (See Appendix A and table 3). 


\section{PRESENT STATUS OF THE AUTOMATED SYSTEM}

The dashed lines illustrated earlier in figure 5 indicate procedures and programs that remain to be written. A list of the programs and their function is given in Table 5. The programs specially written or adapted for this system are underlined. They are grouped into a package called IONPACK. The system is developed to the point that intermediate control and output files can be prepared. Information subsets and final compilation merging and editing remain to be developed.

When the typist is satisfied, a copy is made to be proofread by the abstractor. When all corrections have been made, an archival tape is requested and GPSDC programs are used to convert the archival tape to a GPSDC file and print the file using the extended character printer. If any mistakes are found in the printout, corrections are made in ATS and a new archival tape is requested.

IPABSI is used to read this file and generate the files required by the data center. These files are: The abstract print file, the card image file, the reference file and the raw ion data file. DGMDMP is used to print the abstract print file and the card image file. The abstract printout is used as an archival record of the abstracts that have been processed. The card images are printed on $5 \times 8$ cards. The cards containing the citations are used as document control care replacements. They indicate which papers have been processed. The ion data cards are sorted manually by ion and provide a manual alternative to the machine readable ion data file. (At a later date these cards may be 
Table 5. List of Programs Used

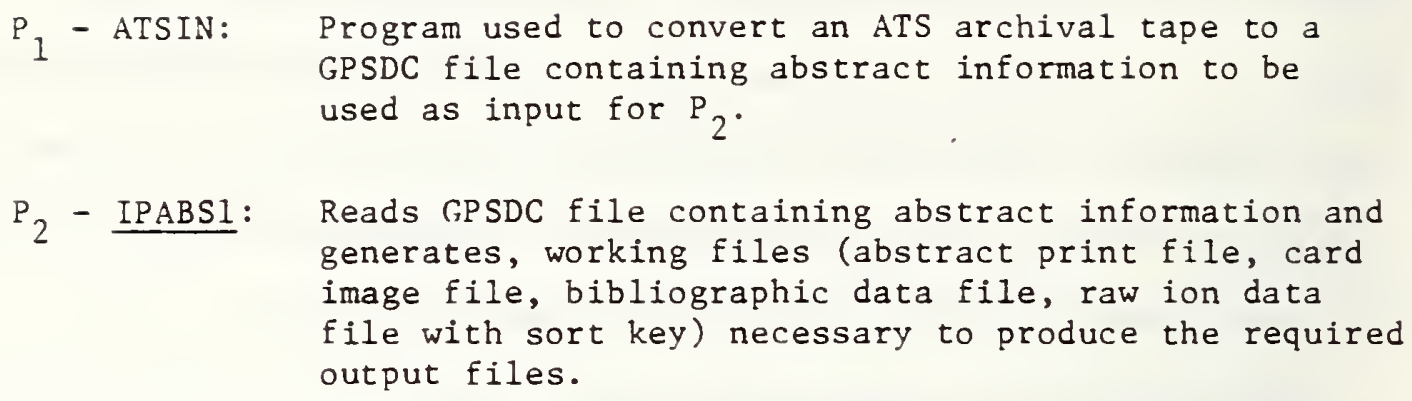
GPSDC file containing abstract information to be used as input for $\mathrm{P}_{2}$.

$\mathrm{P}_{2}$ - IPABS1: Reads GPSDC file containing abstract information and generates, working files (abstract print file, card image file, bibliographic data file, raw ion data file with sort key) necessary to produce the required output files.

$\mathrm{P}_{3}$ - DGMDMP: Prints card image file generated by $\mathrm{P}_{2}$ (ion data + DOC, control replacements) to produce $5 \times{ }^{2} 8$ document control replacement.

$P_{4}$ - WREF: Inputs bibliographic data file and outputs an unsorted author file with sort key and a reference file.

$\mathrm{P}_{5}$ - IPSORT: Sorts the raw ion data file generated by $\mathrm{P}_{2}$.

$P_{6}$ - ISTRIP: Inputs the sorted raw ion data file, strips the sort key from the entries and write them out as a GPSDC file.

$P_{7}$ - IPASRT: Sorts the unsorted author file generaied by $P_{4} \cdot$

$P_{8}$ - MERGE: To be developed later. 
dispensed with). The raw ion data file is added to the year's cumulative raw fon data file. The cumulative files for each year are combined to form a master cumulative file.

IPSORT is used to sort a raw ion data file when the evaluator wishes to see the materlal ordered by ion. ISTRIP is used to remove the sort key from a sorted ion data file and generate a GPSDC file. DGMDMP is used to print the flle on the extended character printer.

The GPSDC file from ISTRIP can be edited using EDBOSS or it can be converted to an ATS archival tape and loaded into ATS for editing. The next sections contain detafled instructions for each computerized step of the procedure, and form an operating manual for the present data center.

\section{KEYBOARDING THE ABSTRACT}

\subsection{Format of the abstract}

The abstract is to be keyboarded into the Department of Commerce AIS system using a model 37 teletype or an equivalent terminal. The standard GPSDC method of keyboarding should be used to get the characters that are not in the 96 character ASCII set. Appendix A contains all characters that are defined in GPSDC. 5

The previous example in figure 3 shows a sample abstract as it would be keyboarded. The document control number is on the first line beginning in position 1. The bibllographic information is next. The first author's surname begins in position 7 followed by his initials. The authors are separated by semicolons. The title is separated from the authors and the fournal by double daggers. The Chemical Abstracts abbreviation is used for the journal. The volume number is to be bold 
face (put red hats over the number). The bibliographic information ends with the year in parentheses. The lines of bibliographic information shall not extend past position 60 . While the first line begins in position 7 , continuation lines shall begin in position 9.

The ion data line 1 s flagged by a section mark (a red $Z$ ) in position 1 . The ion formula begins in position 6 . Only the document control number and flags are allowed in positions 1 thru 6 . Flags shall always be in position 1. The reactant formula begins in position 27 . The other products formula begins in position 47 unless the reactant formula runs over the space allotted, in which case it starts two spaces after the reactant formula. The measured value shall be in positions 57 to 76 the decimal point shall be in position 62 . The method shall be in positions 77 to 79. If there is a heat of formation it shall be in positions 85 to 93. The decimal point shall be in position 92 . This field will normally be blank.

The name of the reactant follows. It shall begin with an open parenthesis in position 27. If the name is so long that it would extend past position 115, it may be continued on the next line. The name may be followed by up to three comment lines. If the comment is a parenthetical comment, the open parenthesis shall be in position 9. Regular comments shall begin in position 6 . Do an extra carriage return before the next ion data line.

An abstract shall be terminated by a dagger (red $V$ ) in position 1. It is important that the abstracts be in increasing order of ID number. If they are out of order the abstract and reference files will be out of order. 
7. CONVERTING ATS KEYBOARDING TO GPSDC FILE

7.1 Requesting an ATS Archival Tape

The procedure for requesting an archival tape is to first put

the document or documents in the archival queue. The command used is $\underline{x}$; archive; document name.

The AQR form must then be filled out and sent to operator 0 (zero) and operator 20. A sample form is shown in figure 6. The form must request that the archival tape be sent to NBS via the NBS shuttle.

\subsection{Converting the Archival Tape to GPSDC}

The program ATSIN is used to convert the ATS Archival tape to a GPSDC file for processing by the programs in IONPACK. The tape must be labeled for use on the NBS computer. The first three letters of the label shall be ION. This may be followed by the last three numbers of the Department of Commerce tape number for the reel. Make a $5 \times 8$ card with the new tape label and the Department of Commerce tape number. The card will contain the date the material was archived, a description of the materfal archived, and the date the tape was received. The card shall then be filed in the tape file box. Record all movement of the tape of the $5 \times 8$ card. Figure 7 shows a sample card.

The job request card, a listing of the run, and a 360 printout of the CPSDC input file are shown in flgures 8,9 , and 10 respectively.

The flrst card is the standard run card. The fob is run under $\mathrm{N}$ priority. This means it is run overnight for cheaper computer costs. The second card assigns the GPSDC program file. The third card invokes the collector to gather the routines required for this run. The fourth card assigns the ATS archival tape as file 8 . The U9V means the tape is 9 


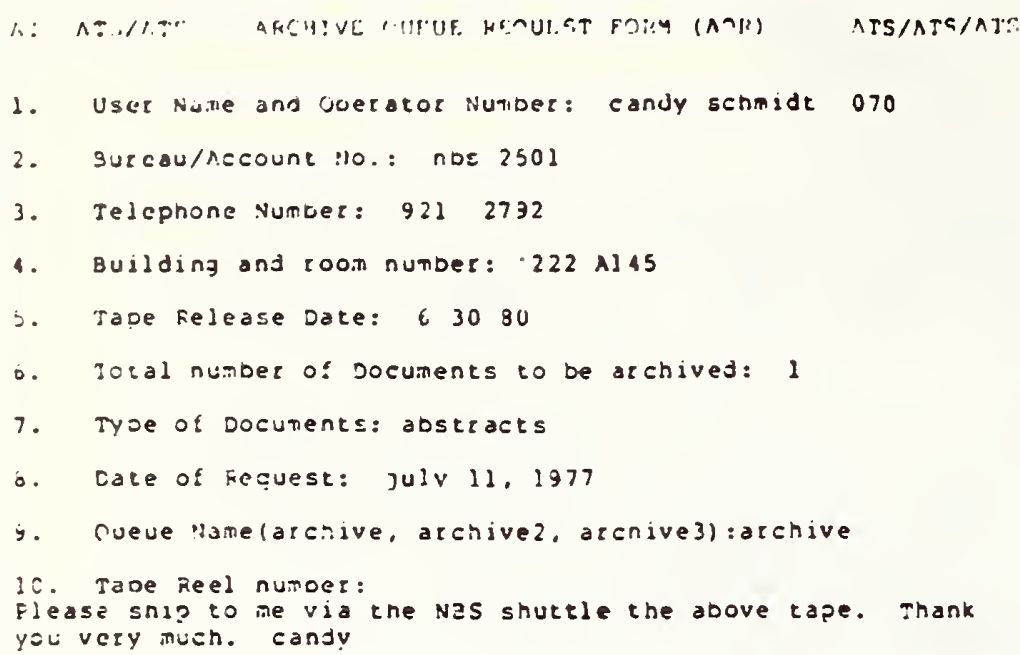

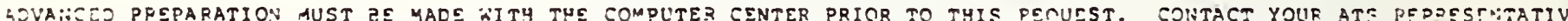

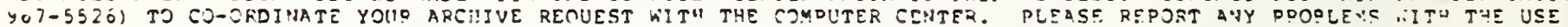

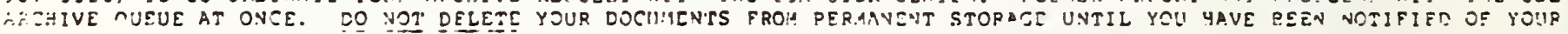
FEEL NUUYZER. 
009523

CS003 9 Track ATS labeled tape

? ASG, TJ 8., U9V, $\mathrm{CSOO} 3$

contains abstract entries $3476-3484 \quad 6-20-77$

Figure 7. GPSDC tape description to be recorded on $5 \times 8$ card and kept in the tape file box. 


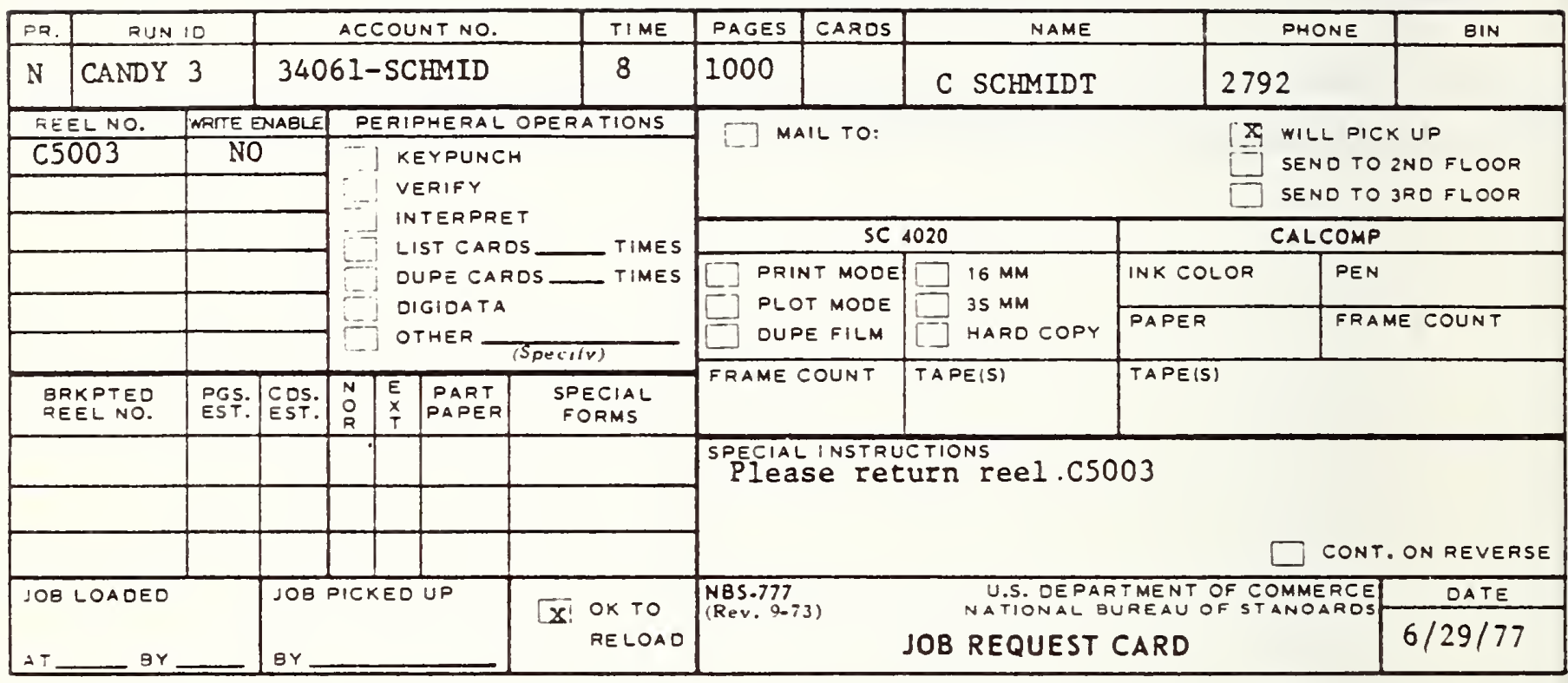

Figure 8. Job request card for ATSIN run. 


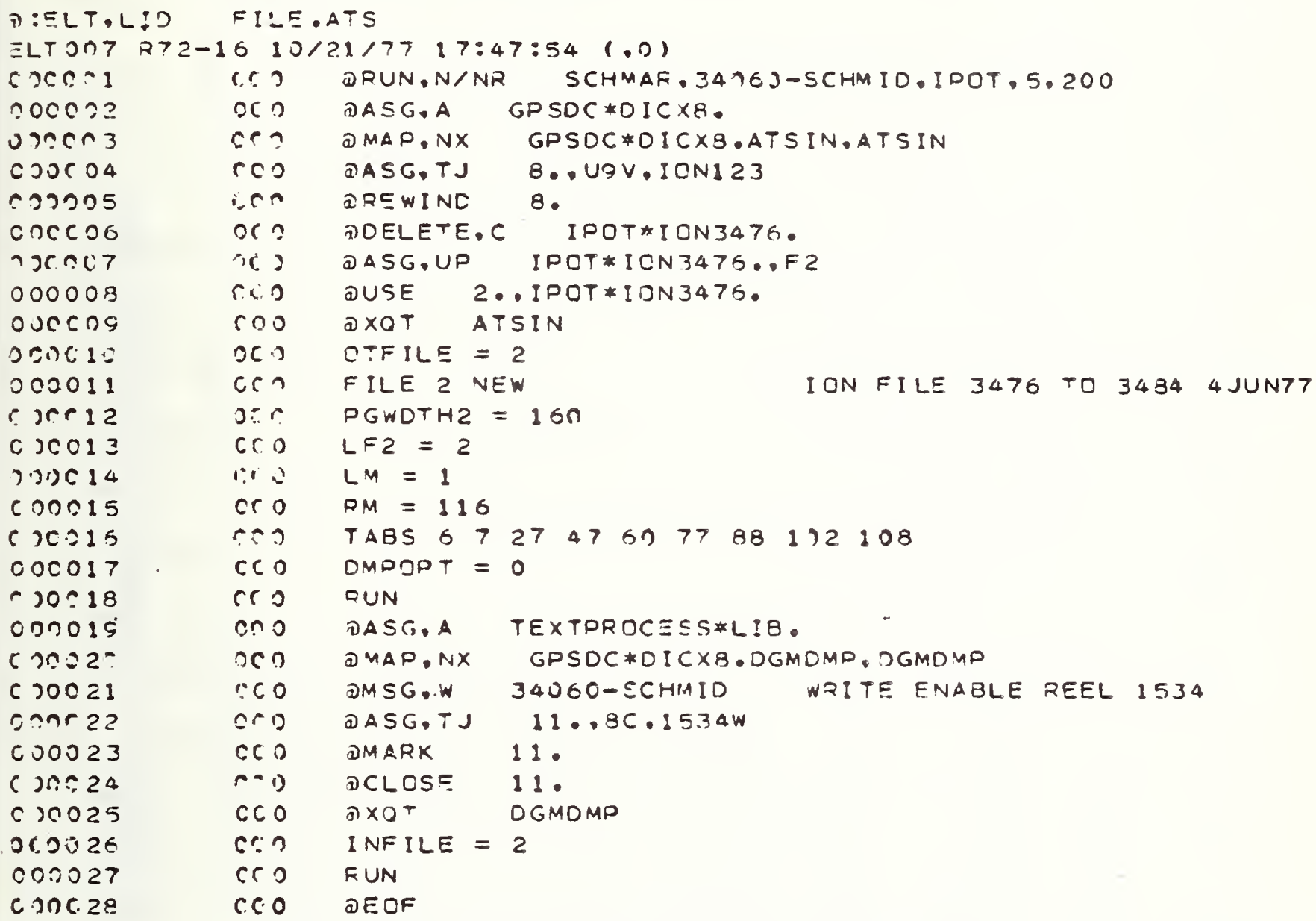

Figure 9. 'Listing of ATSIN run. 


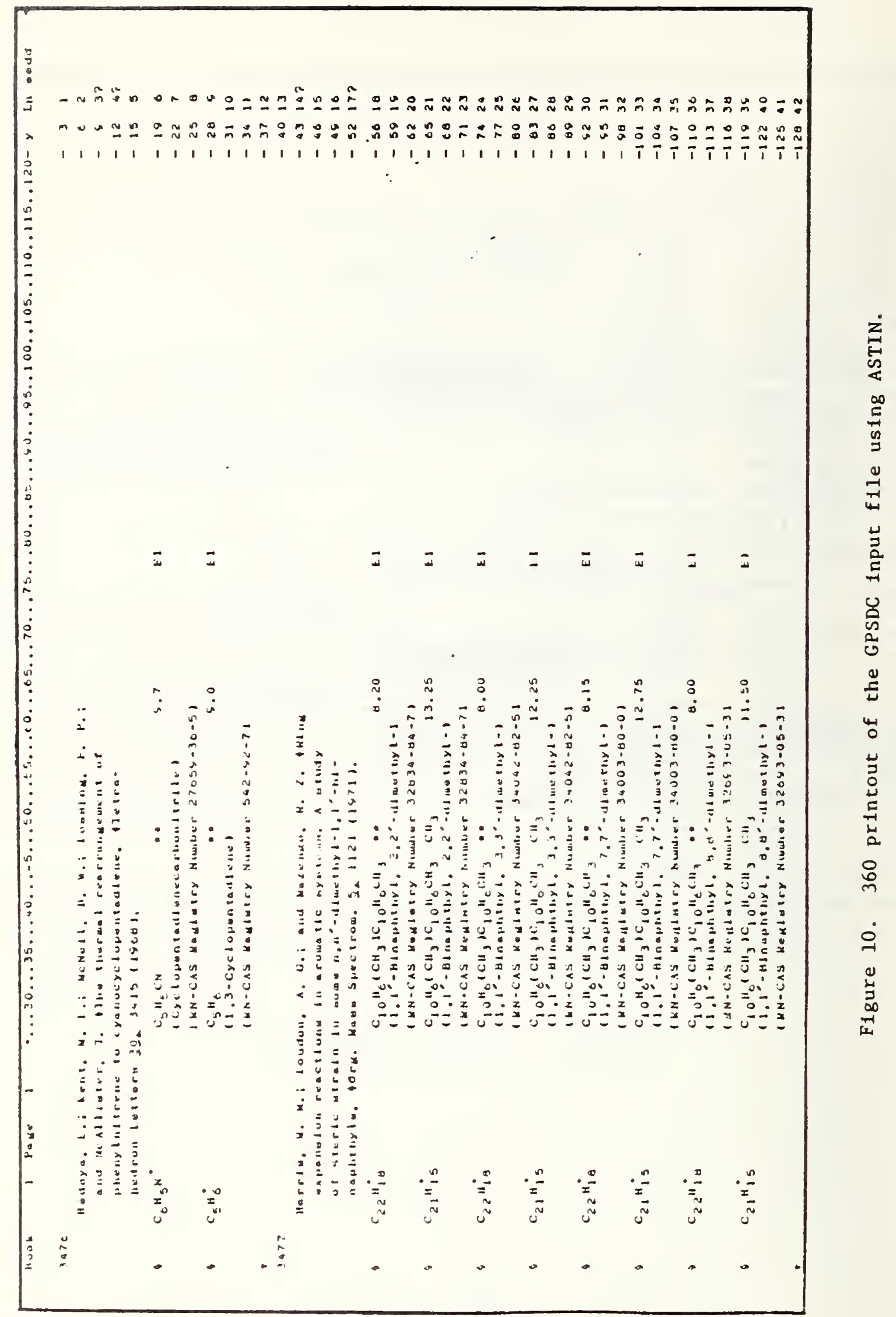


tracks, $1600 \mathrm{bpi}$. The $6 \mathrm{th}, 7 \mathrm{th}$, and $8 \mathrm{th}$ cards assign a file called IPOT:ION3476 as file 2. This name was used because the tape contains abstracts for papers 3476 thru 3484. The 9 th card starts execution of the program ATSIN. Cards 10 and 11 tell the program the output file is file 2 and 1 is to have GPSDC label ION FILE 3476 to 3484 . These cards are the beginning of the random order data which is described in more detail in the GPSDC users manual.

The next map card invokes the collector to gather the routines required to print the GPSDC file created by ATSIN. The next two cards assign a tape for DGMDMP to write which is printed on the IBM 1403 printer using the GPSDC train. The label and description is put on a $5 \times 8$ card and stored in the tape file box (figure 11). The mark and close cards put end of files at the beginning of the tape so that a lot of useless printout is not received if the run does not write on the tape. Combining smaller inpur files into larger ones is done using EDCARD or EDBOSS.

\section{GENERATING THE REQUIRED OUTPUTS}

The production of the various required outputs necessitates several steps. The program IPABSI reads the GPSDC file and writes three new GPSDC files and a binary file. The file input which was generated as file 2 in the previous run is assigned file 1. The file of abstracts to be printed is output on file 2. The file of card images to be printed on $5 \times 8$ cards is output on file 3. The reference file is written on file 4 and the raw ion data file is written on tape on unit 7 . The program DCMDMP is used to generate the tapes used to drive the 360 printer to print the abstracts, the document control card replacements and the ion data cards. 
NBS

0409

(a) ASG,TJ 11., 8C, 0409 assigned to 30062-WEBBWI

To be used as DGMDMP tape

Printed abstract entries 3476-3484

29 Jun 77

Figure 11. Description of tape that is assigned to print the GPSDC file created by ATSIN. 
The job request card, a listing of the run, a 360 printout of the abstract file, and the $5 \times 8$ card describing the tape are illustrated in figures 12 through 15 respectively.

Note in the run deck, that the next three cards beginning after the FILE 1 OLD card should have the words ABSTRACT, CARD, and REF beginning in column 26. The dump option card (DMPOPT) will produce a one line dump if DMPOPT $=1$, and no dump if DMPOPT $=0$. The miscellaneous card (MISC) provides the option of diagnostic printout if desired (e.g. printing the sort key).

The raw ion data file produced by this run will be kept for some time and will be merged with the yearly cumulative raw ion data file which in turn will be merged with a total cumulative file. Therefore the file should be put on a labeled tape that has been purchased. A description of the file and the date of the run will be written on the $5 \times 8$ card for the tape that is kept in the tape file box.

The raw ion data file consists of a 55 word sort key followed by the ion data line, name, and comments in GPSDC characters packed two characters per word. There is an octal 777777777777 word separating each line. The file is written on tape using NTRAN and cannot be read as a GPSDC file.

\subsection{Printing the $5 \times 8$ Cards}

The DGMDMP program is used to generate the tape for printing the $5 \times 8$ cards. It is necessary to supply the $5 \times 8$ card stock to the computer room. Examples of the job request card, a listing of the run, and a 360 printout on $5 \times 8$ cards are shown in figures 16, 17, and 18 respectively.

\subsection{Sorting the Raw Ion Data File}

When IPABSI generates the raw ion data file it puts a sort key at the beginning of each ion data line. The program IPSORT is used to order the data by fncreasing atomic number of the elements in the 


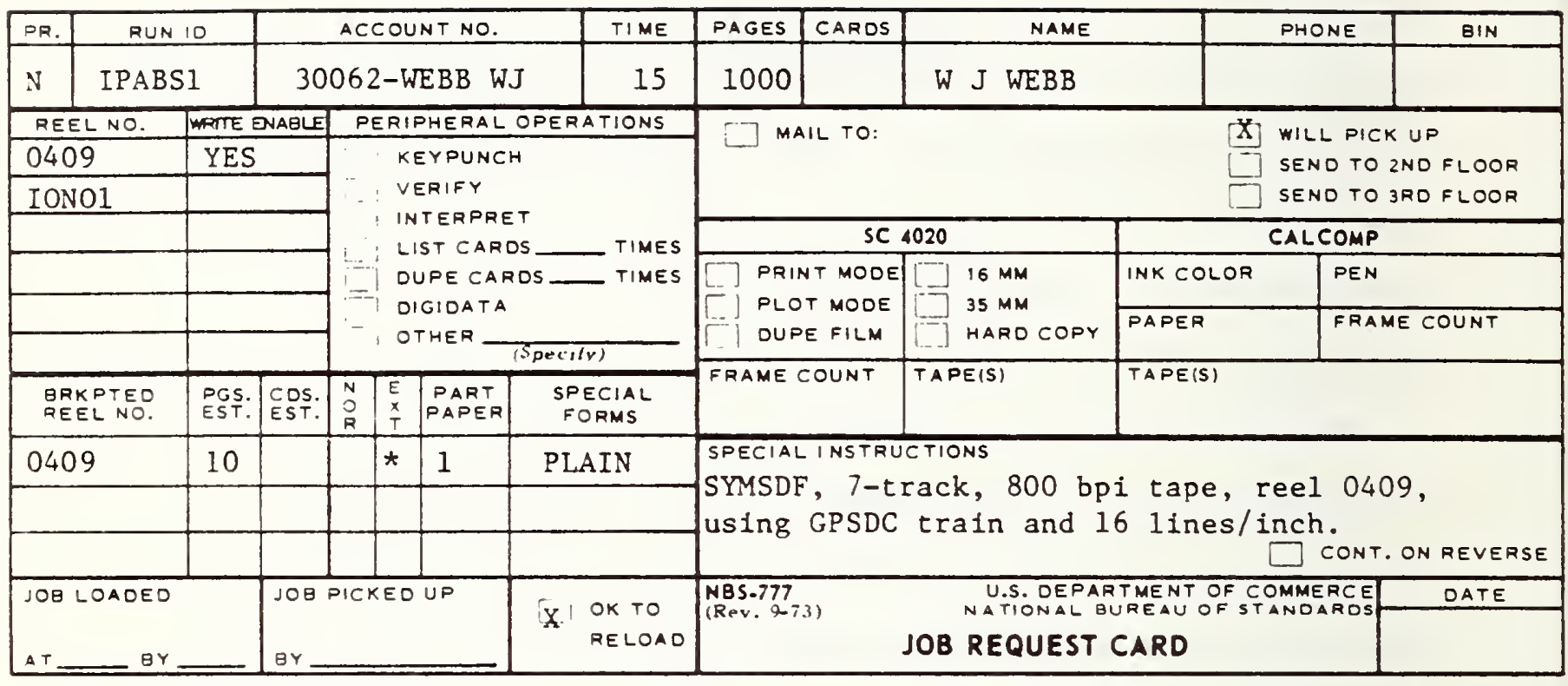

Figure 12. Job request card for IPABSI run. 
D:ELT.LID FILE.ABS

ELTOCT R72-16 1C/19/77 18:01:27 (.0)

0000 こ 1

000002

IC D DRUN,N/NR IPABSI.34

$0 \operatorname{coc} 3$

CCO DASG.A GPSDC $\#$ ICX8.

c COO 04

300

CCO

cos

on $0: 5$

DASG,A IPOT $* I O N P A C K$.

$000006^{\circ}$

กดกวด

OCO

000

$00 \mathrm{CC} 08$

CCO

000009

000010

$000<11$

$000 \mathrm{C} 12$

100013

$c 00214$

DASG,A TEXTPFOCESS*LIB.

DASG,A GPSDC $\$ 3476-3484$.

DUSE 1.,GPSDC $* 3476-3484$.

ФDELETE,C IPOT*ABS3476-3484.

DOD

000

500

$O C O$

oco

cos

000015

000016

$\cos 17$

QASG,UP IPOT*A3S3476-3484,FF 2

DUSE 2.IIPOT*ABS3476-3484.

DDELETE,C IPOT $* C R D 3476-3484$.

DASG,UF IFOT \#CRD 3476-3484 . .F 2

QUSE 3. IPOT*CRD 3476-3484.

DDELETE,C IPOT*REF 3476-3484.

$\mathrm{DCO}$

QASG,UP IPOT*REF $3476-3484$. .F 2

oro

000

CCO

300019

AUSE 4 ..IPOT *REF3476-3484.

DASG,T IPOT*RAWION3476..8C9.IONOIW.400O

DMSG.W 34C 60-ROSENS WRITE ENABLE TAPE IONOI

200

000

000020

QUSE

7 .. IPOT TRA WI ON3476.

DMAP, INX IPABS

500

$\mathrm{CCO}$

000022

LIB IPOT \#IONPACK

LIB GPSDC*DICX8

000

000

oc 0

or.o

cco

300

oro 0

sco

CC.O

n.: 0

cco

DCo

$\mathrm{CCO}$

oco 0

CCO

000

600

000

000

LIB TEXTPROCESS*LIB

IN IPABSI

DXOT IPABS

FILS 1 OLD

FILE 2 NEW

FILE 3 NEW

FILE \& NEW

DMPOPT $=0$

ABSTRACTS 3476-3484 23JUNT7

$M I S C$ ¿O

RUN

DMARK 7 .

DCLOSE 7 .

๑MAP,NX GPSDC*DICX8.DGMOMP,DGMDMP

DMSG, W 30062-WEBBWI WRITE ENABLE REEL 0409

DASG,TJ $11 \ldots 8 C .0409 \mathrm{~W}$

DMARK 11.

DCLOSE 11.

จ XOT DGMDMP

YNF ILE $=2$

RUN

OCO DEOF

Figure 13. Listing of IPABSI run. 
- nme nor DuO

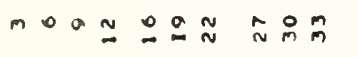

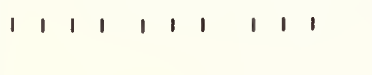

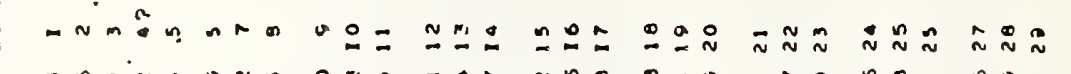

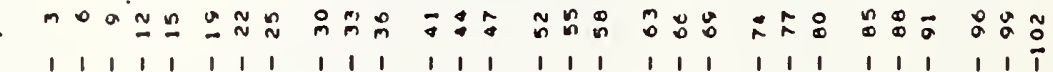
$\begin{array}{llllllllllllllllllllllllllll}1 & 1 & 1 & 1 & 1 & 1 & 1 & 1 & 1 & 1 & 1 & 1 & 1 & 1 & 1 & 1 & 1 & 1 & 1 & 1 & 1 & 1 & 1 & 1 & 1 & 1 & 1 & 1\end{array}$

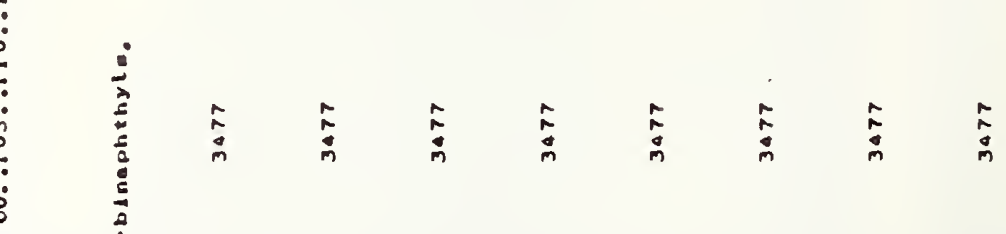<smiles>[CH]C=C[CH-]</smiles>
(a) : : 桨

$i \stackrel{x}{2}$

$\therefore:$

每

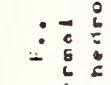

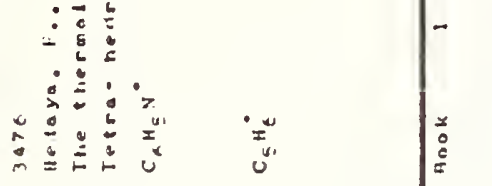


IONO1, 9 track, labeled tape

c ASG, T RAWION 3476., 8C9, IONO1, 4000

From output file 2, printed abstracts $3476-3486$
$3-10-76$

29 Jun 77

Figure 15. Description of tape containing raw ion data file is. recorded on $5 \times 8$ card and stored in the tape file box. 


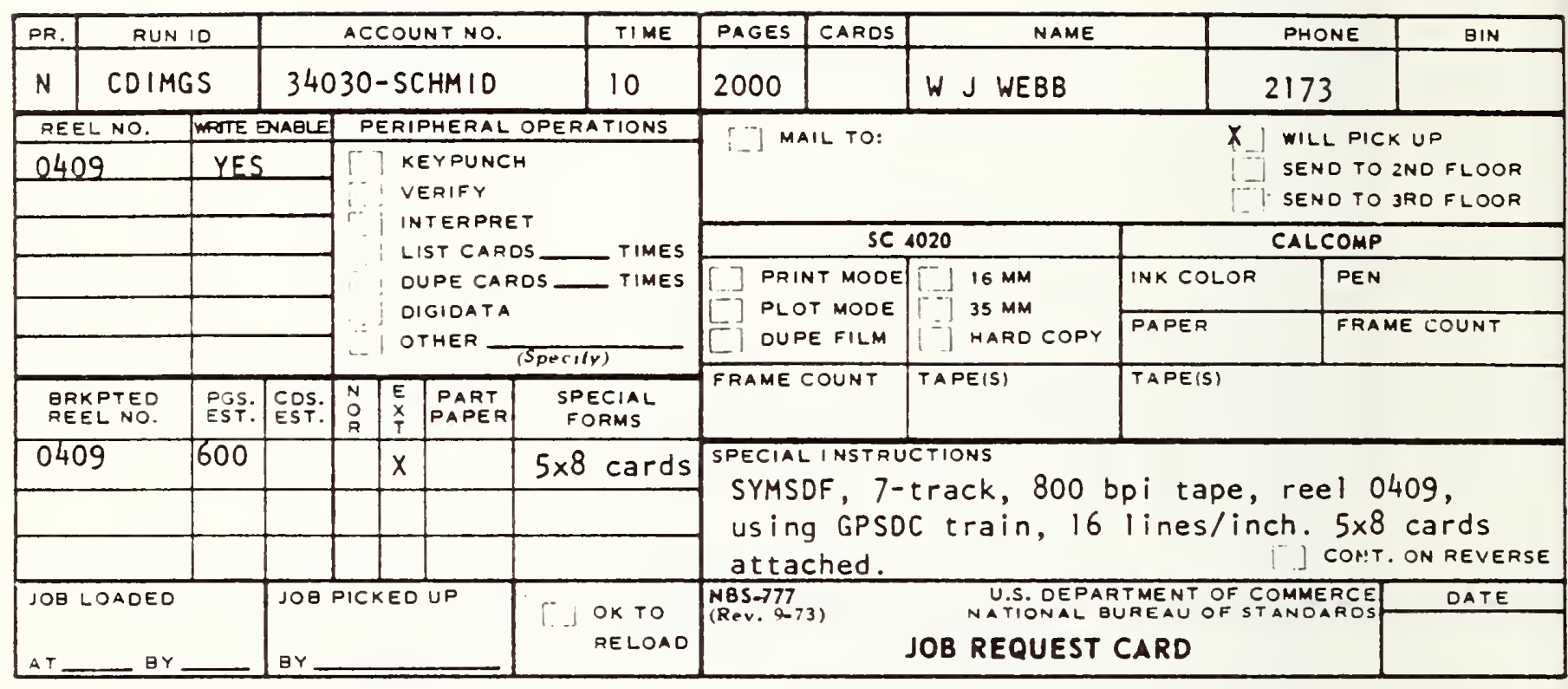

Figure 16. Job request card for printing card images on $5 \times 8$ card stock. 


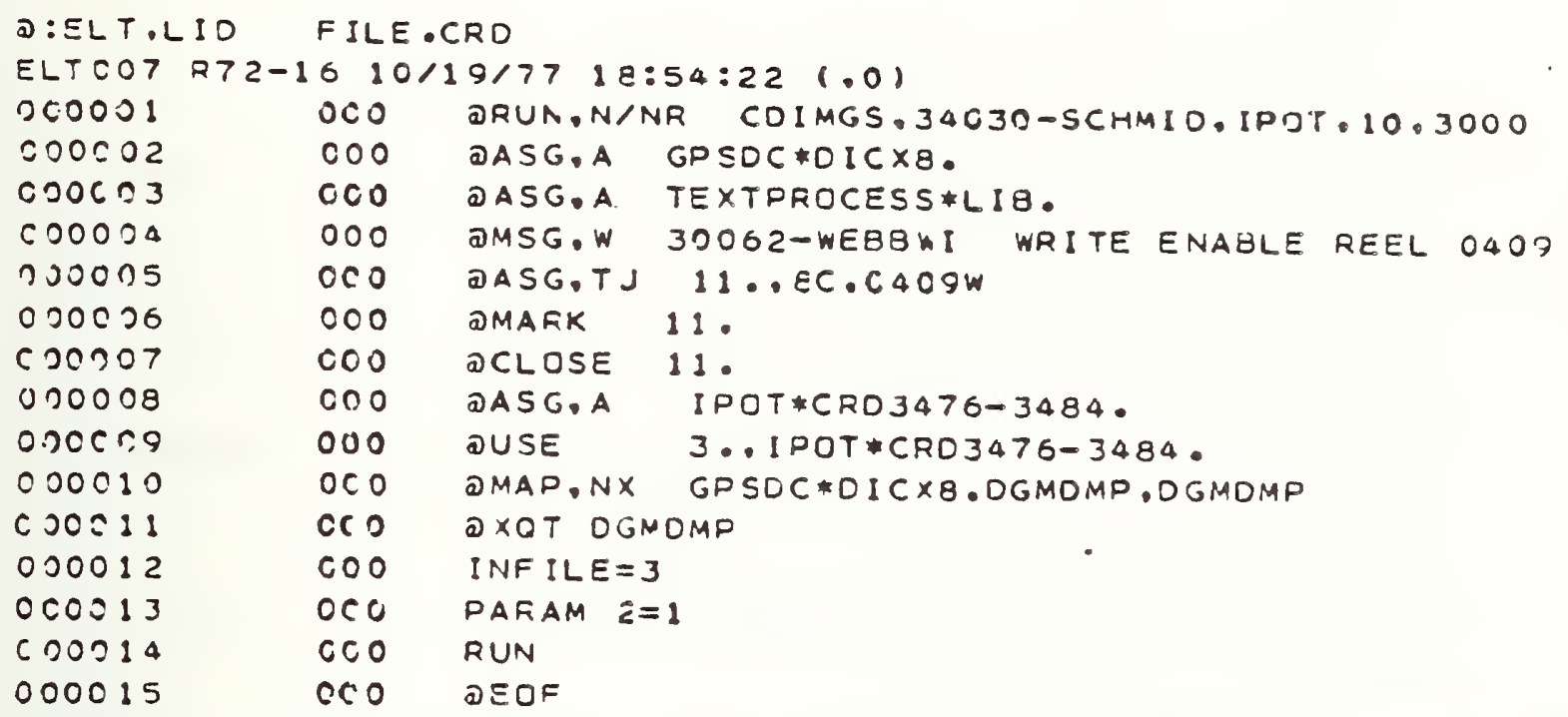

Figure 17. Listing of run using DGMDMP to print the card image file. 


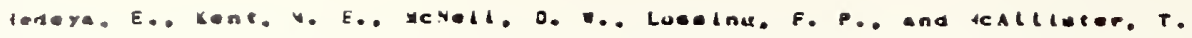

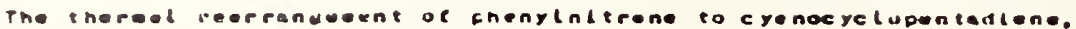

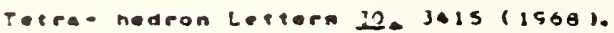

$\cos _{\mathrm{H}^{2} \mathrm{~N}}$

$\mathrm{C}_{\mathrm{S}} \mathrm{H}_{\mathrm{S}} \mathrm{CH} \bullet$

(Crelopentadienecertonterleb

5.7

EI 1470

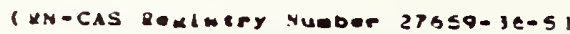

$\mathrm{C}_{5} \mathrm{~N}:$

$\mathrm{C}_{5} \mathrm{H}_{6} \bullet$

(1).j-crelopeotadienel

9.0

E 1 J4 7 B

( KN-CAS HeUtmery Number 542-92-7)

Yarrlu, M. M.. Lovan, A. C.. Lod yazenus, R. Z.

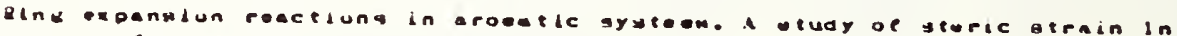

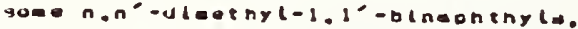

aru. Hats Spectoon. 5. $1123(1971)$.

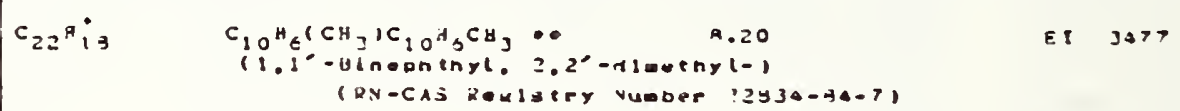

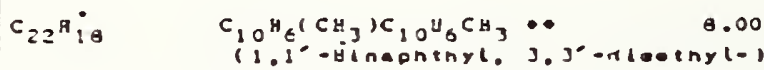

E 8 3.77

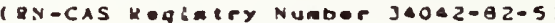

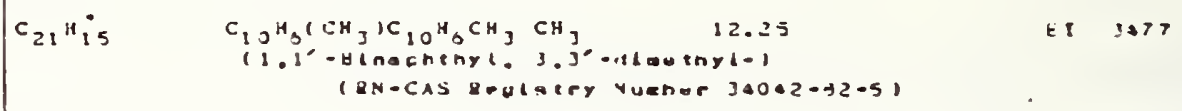

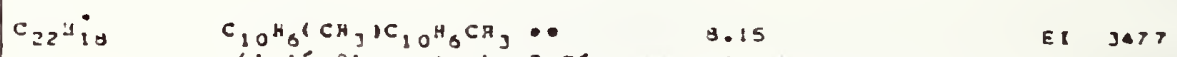

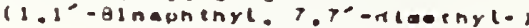

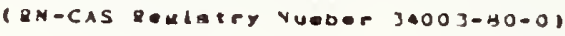

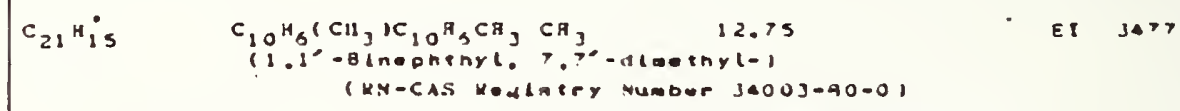

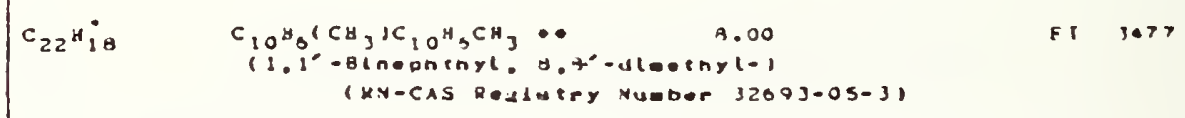

\begin{tabular}{|c|c|c|c|c|}
\hline $\mathrm{C}_{21} \mathrm{H}_{15}$ & 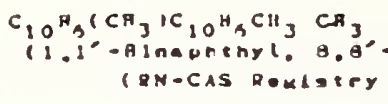 & $\begin{array}{c}11.50 \\
\text { aumber } 32093-0,31\end{array}$ & E I & 3477 \\
\hline $\mathrm{C}_{21} \mathrm{H}_{15}$ & 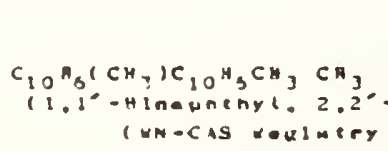 & 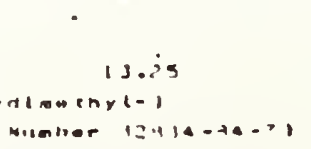 & f. I & 3477 \\
\hline
\end{tabular}

Figure 18. 360 printout of card 1mages on $5 \times 8$ card stock using DGMDMP. 
ion. The program can be used on the original raw ion data file, the cumulative raw ion data file, or to combine and sort serveral raw ion data files on the same input tape. The sorted raw ion data file produced by this run will be kept for some time. It may be merged with other files to produce cumulative sorted raw ion data files. Therefore the sorted file should be written on a labeled tape that has been purchased. A description of the file and the date of the run shall be written on the $5 \times 8$ card for the tape that is kept in the tape file box.

Examples of the job request card, a listing of the run, and the $5 \times 8$ card describing the tape follow in figures $19-21$.

In this run the input file is assigned as file 7 and is the labeled tape generated by the earlier IPABS run. The output file is a labeled tape and assigned as file 8. The card following the QXQT card is the parameter card for IPSORT in 315 format. The first number is the number of the input file, the second is the number of the output file. The third number is the number of files to be read of $f$ the input tape and sorted together.

8.3 Printing the Raw Ion Data File

The program ISTRIP removes the sort keys from the records and writes a CPSDC file. The GPSDC file can then be printed using DGMDMP. This is the method used to print the contents of the sorted files. The program starts each ion on a new page.

The job request card, a listing of the ISTRIP run, and a 360 printout of the sorted ion data are illustrated in figures 22,23 , and 24 respectively. 


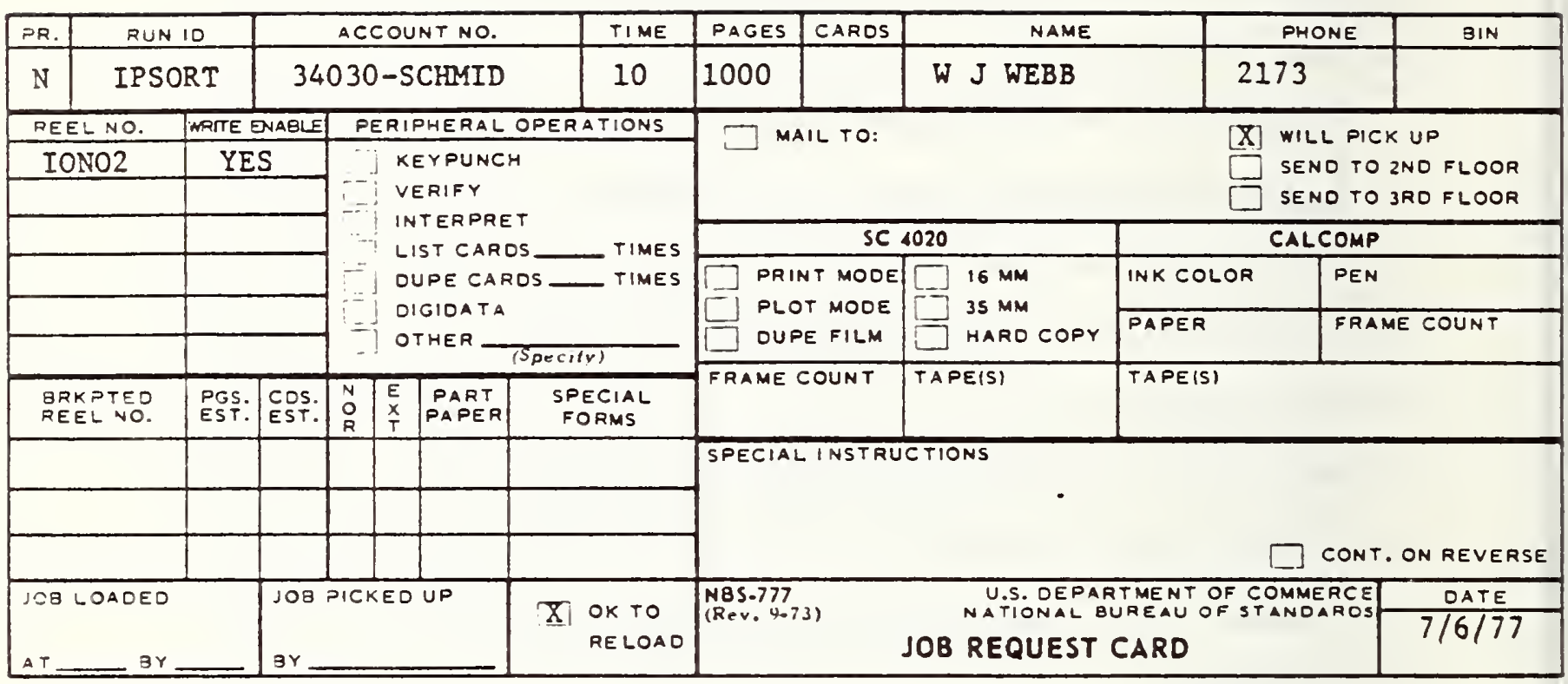

Figure 19. Job request card for IPSORT run. 


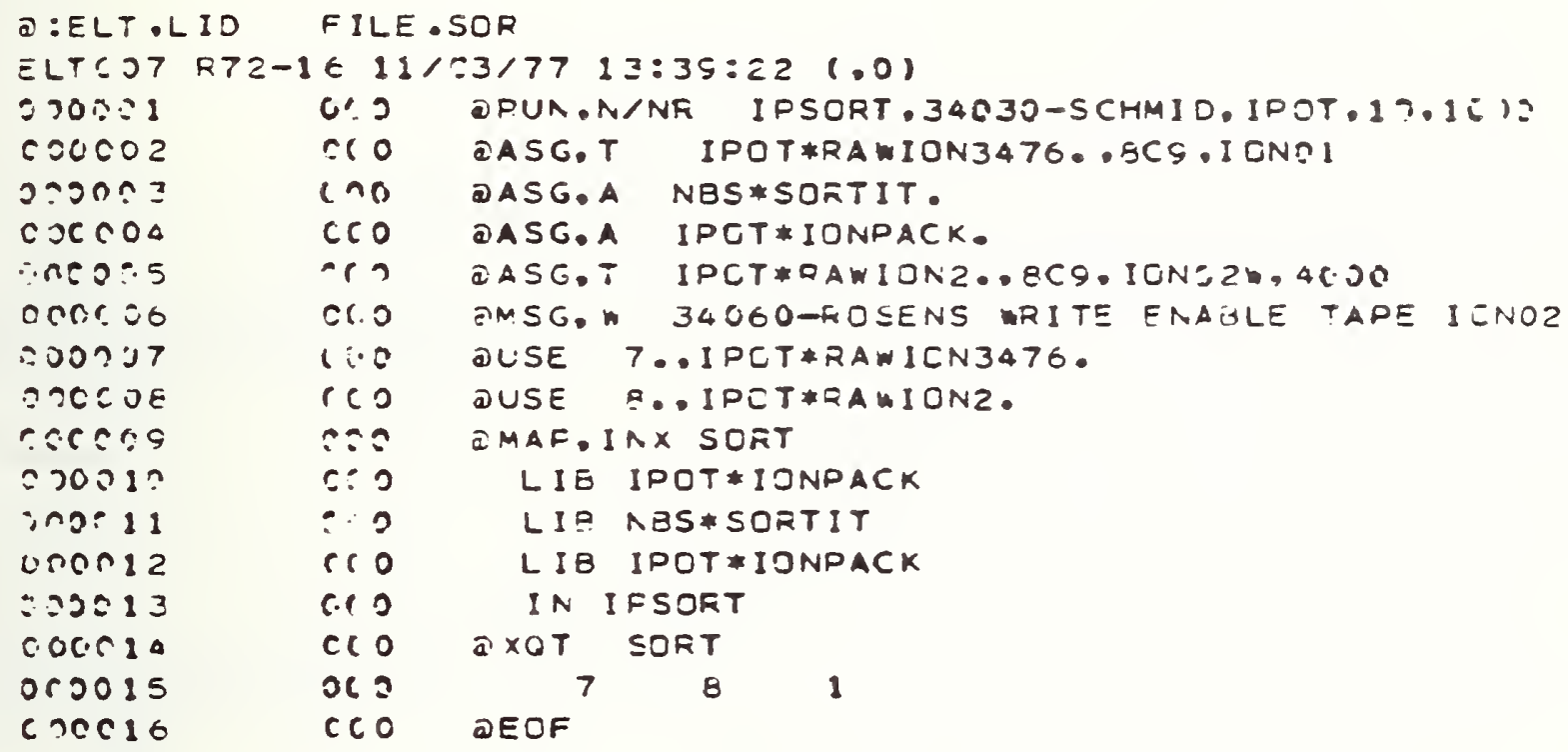

Figure 20. Listing of IPSORT run. 
IONO2, 9 track, prelabeled tape

$3-10-76$

e ASG, T IPOT:KRAWION2,, 8C9, IONO2 W, 4000

contains sorted raw ion data 3476-3484

13 JuI 77

Figure 21. Description of the sorted raw ion data file should be recorded on a $5 \times 8$ card and kept in the tape file box. 


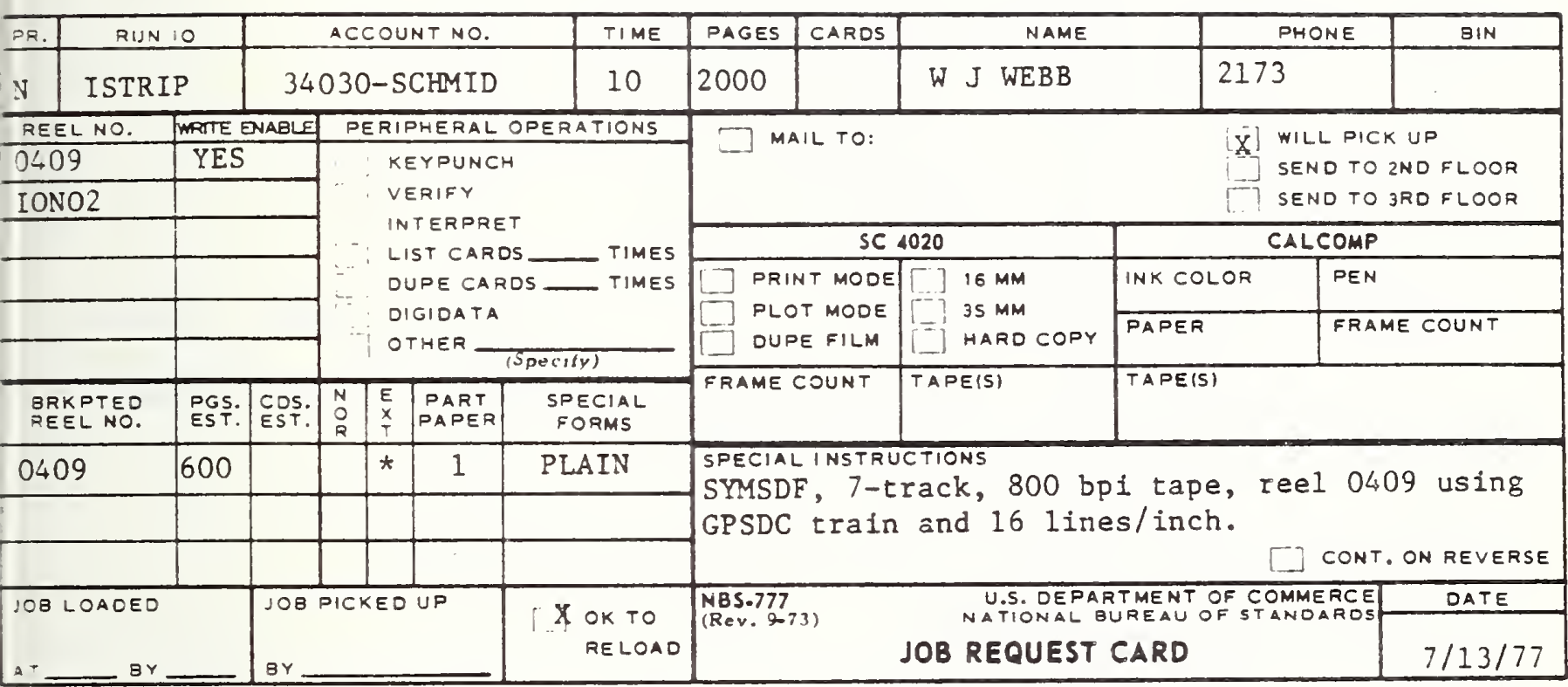

Figure 22. Job request card for ISTRIP run. 


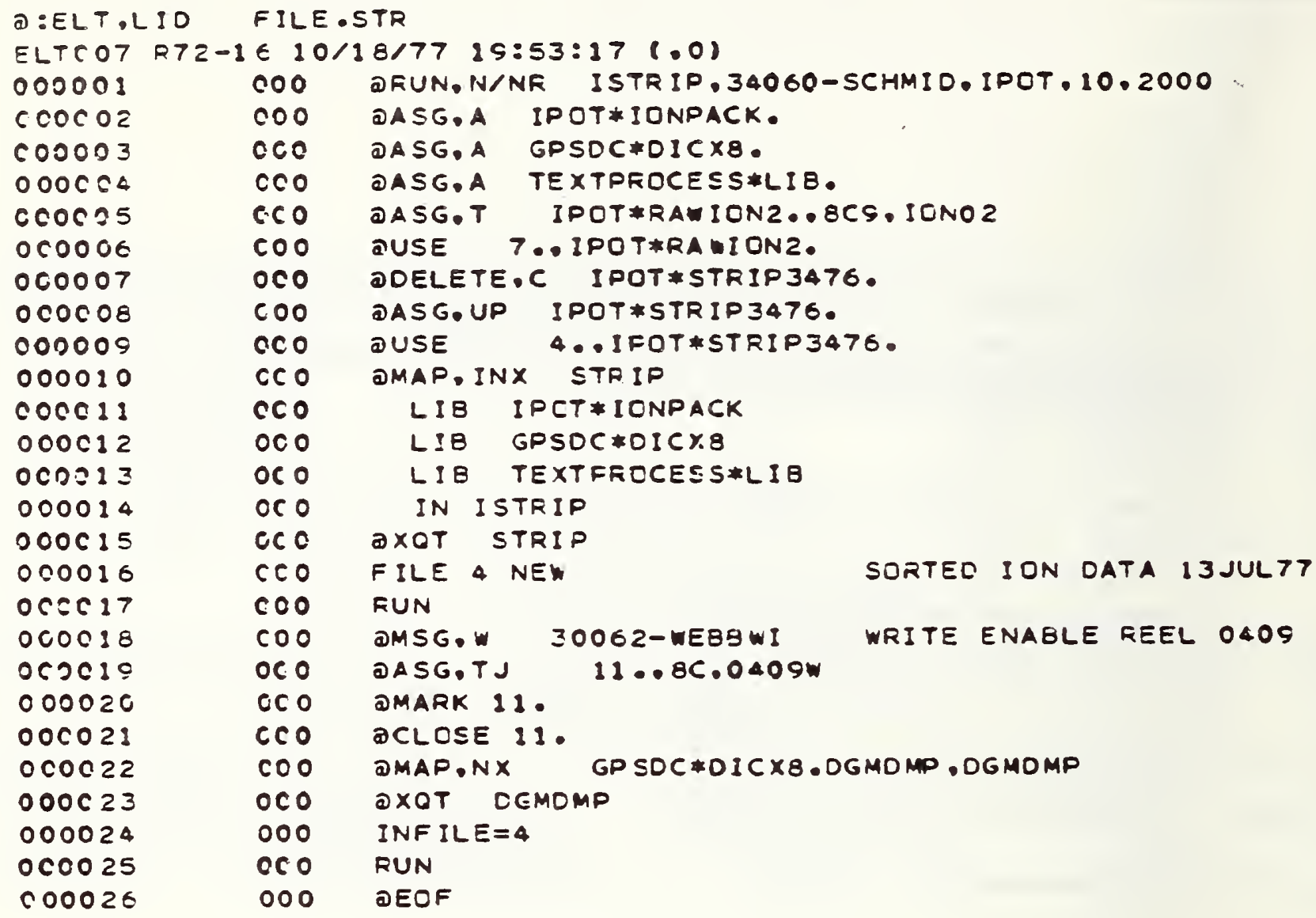

Figure 23. Listing of ISTRIP run. 


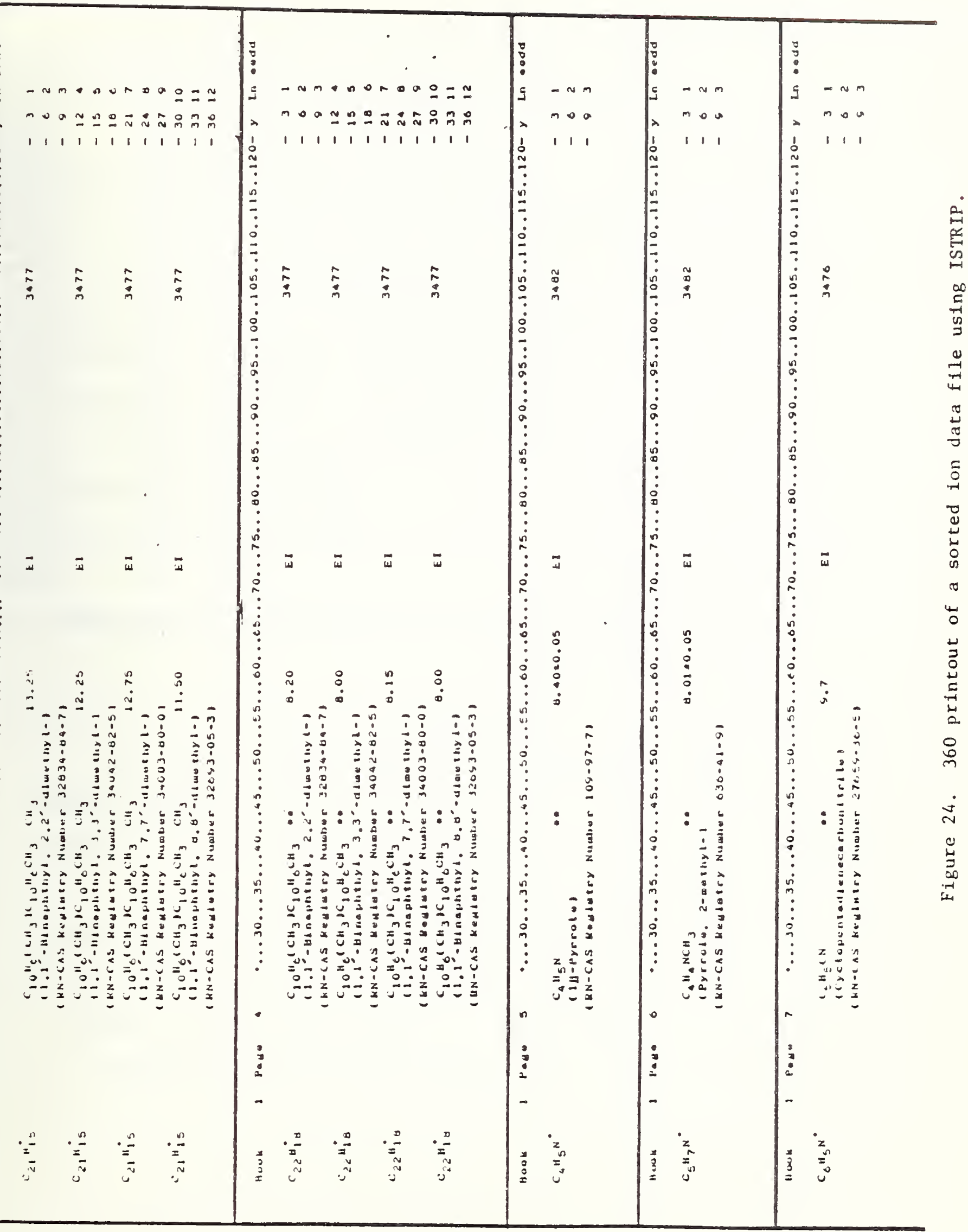




\section{4 Program WREFS}

This program is designed to input the bibliographic data file and output a reference file and an unsorted author file. The bibliographic data file is a GPSDC f1le.

Each entry begins with the identification number enclosed in brackets in columns $1-6$ of the first line. The authors begin in column 8 . They are separated by semicolons and terminated by a double dagger. The authors are followed by the title which is terminated by a double dagger. This is followed by the citation. The output reference file is identical to the input file except the semicolons between authors are replaced by commas and the double daggers are replaced by blanks. The unsorted author file is generated by writing out each author followed by the idiot number. This file is later sorted and entries for a given author merges to generate the author index.

DGMDMP may be used to print the reference file. A sample test run of WREFS is shown in figure 25.

\subsection{Sorting the Author Index Entries}

IASORT is designed to sort the author index entries. The Exec 8 version of SORTIT is used to interface with the SORT/MERGE package. IASORT is a main program used to call SORTIT. SORTIT calls two routines IASRDS and IASWRT to read and write files or tapes.

IASTRP is designed to input an author file with sort key, strip off the sort key and output an author index as a GPSDC file. The GPSDC file can then be printed using DCMDMP. A listing of the IASORT run, IASTRP, and a 360 printout of the sorted author file are shown in figures 26, 27 , and 28 respectively. 
จ:SL:.LID FILE.WRF

ELTOOT O 72-16 11/23/77 18:21:09 (.0)

000001

000002

000003

000004

000005

000006

000007

000008

000009

000010

000011

000012

000013

000014

000015

000016

000017

000018

000019

000020

000021

000022

000023
000 DRUN.N/NR WREFS.34030-WEBBWI.IPOT.10.100

OOO DASG.A IPOT IONPACK.

OOO DASG.A TEXTPROCESSTLIB.

OOO DASG.A GPSOC\#OICX8.

OOO DMAP.IS REFILE

000

000

000

000

000

000

000

000

000

000

000

000

000

000

000

000

000

LIB IPOT IONPACK..GPSOC\#OICX8. TFXTPFJCESS*LIE.

LIB IPOT IONPACK.. GPSDC\#OICX8. TEXTPROCE SS\#LIB.

LIB GPSDC*OICX8

IN VREFS

DASG.A IPOT\#REF 3476-3484.

AUSE $\quad 1$. IPOT REF $3476-3484$.

DDELETE,C IPOT\$BIB3476-3484.

QASG.PU IPOT*BIB3476-3484.

DUSE 2.IIPOT*BIB3476-3484.

DDELETF.C IPOT $\$ A U 3476-3484$.

DASG.PU IPOT*AU3476-3484.

DUSE 3. IPOT $* A U 3476-3484$.

OXOT REFILE

FILE 1 OLD

FILE 2 NEW

FILE 3 NEW.

918LIT. SATCH 3476-3484 27 JUL77

RUN

AUTHOR BATCH 3476-34RA $27 J U L 77$

OOO DEOF

Figure 25. Listing of WREFS run. 


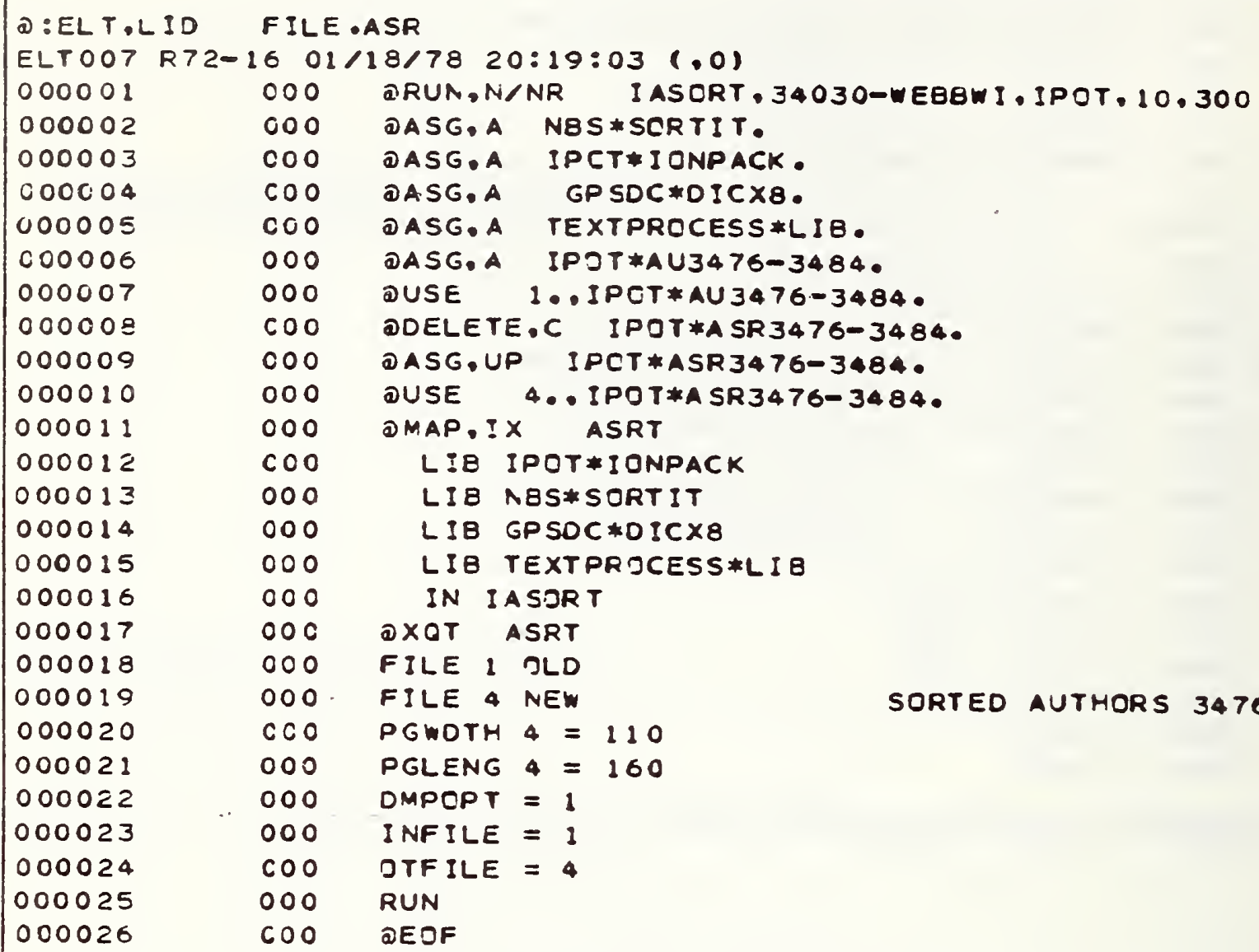

Figure 26. Listing of IASORT run. 


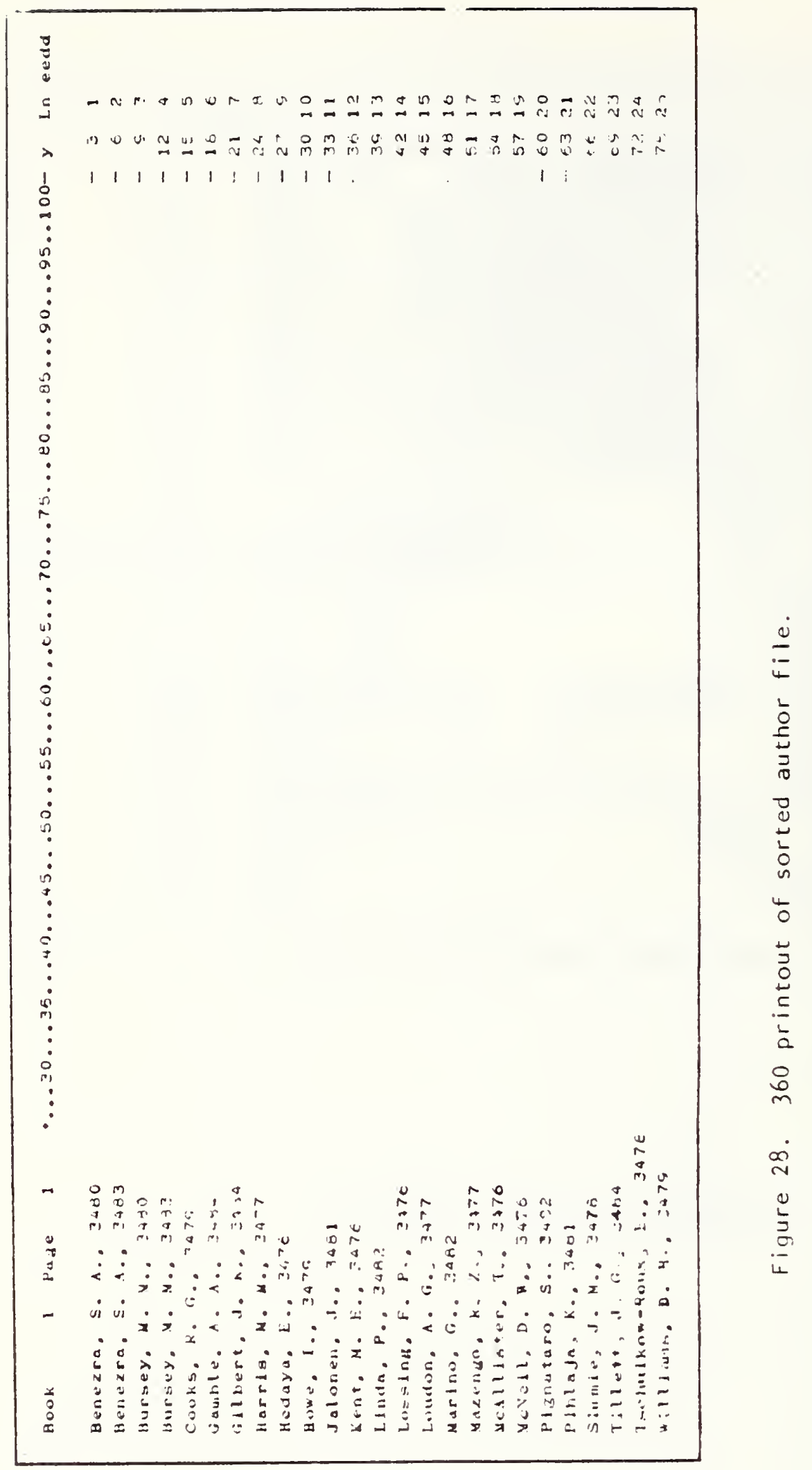


9. ACKNOWLEDGMENTS

We are indebted to Mr. Keith Draxl and Mrs. Candyce Schmidt for their numerous helpful suggestions and assistance in the preparation of this publication. Special appraciation goes to Mrs. Carla Messina, and Dr. William H. Evans for programing contributions. We also thank

Mrs. Janice L. Jones for her valuable secretarial assistance. 
10.

Figure 1.

Figure 2.

Figure 3 .

Eigure 4.

Figure 5.

Figure 6.

Figure 7.

Figure 8.

Figure 9.

Figure 10.

Figure 11.

Figure 12.

Figure 13.

Figure 14.

Figure 15.

Figure 16.

Figure 17.

Figure 18.

Figure 19.

Figure 20.

Figure 21.

Figure 22.

Figure 23.

Figure 24.

Figure 25.

Figure 26.

Figure 27.

Figure 28.
A typical page of the 1977 compilation.

The abstractors form.

Encoded form of the abstract as it would be keyboarded using model 37 teletype.

Schematic of the production of an archival tape of abstracted information.

Separating the abstract into various files.

$A Q R$ form.

GPSDC tape description to be recorded on $5 \times 8$ card and kept in the tape file box.

Job request card for ATSIN run.

Listing of ATSIN run.

360 printout of the GPSDC input file using ATSIN.

Description of tape that is assigned to print the GPSDC file created by ATSIN.

Job request card for IPABSI run.

Listing of IPABSI run.

360 printout of the abstract file created by IPABS1.

Description of tape containing raw ion data file is recorded on $5 \times 8$ card and stored in the tape file box.

Job request card for printing card images on $5 \times 8$ card stock. Listing of run using DGMDMP to print the card image file. 360 printout of card images on $5 \times 8$ card stock using DGMDMP. Job request card for IPSORT run.

Listing of IPSORT run.

Description of the sorted raw ion data file should be recorded on a $5 \times 8$ card and kept in the tape file box.

Job request card for ISTRIP run.

Listing of ISTRIP run.

360 printout of a sorted ion data file using ISTRIP.

Listing of WREFS run.

Listing of IASORT run.

Listing of IASTRP run.

360 printout of sorted author file. 
11. LIST OF TABLES

Table 1. List of Comments and Coding Acronyms.

Table 2. List of Isomer Prefixes in order of sort preference.

Table 3. Numerical Equivalents of GPSDIC Symbols, Isomers Prefixes, Methods and Chemical Element Symbols.

Table 4. Techniques for Ion Energetics Measurements in Order of Sort Preference.

Table 5. List of Programs Used. 


\section{REFERENCES}

1. H. M. Rosenstock, "The Measurement of Ionization and Appearance Potentials" Int. J. Mass Spectrom. Ion Phys. 20, 139, (1976).

2. J. L. Franklin, J. C. Dillard, H. M. Rosenstock, J. T. Herron, K. Draxl, and F. H. Field, "Ionization Potentials, Appearance Potentials, and Heats of Formation of Gaseous Positive Ions," NSRDS-NBS 26, 1-285 (1969).

3. H. M. Rosenstock, K. Draxl, B. W. Steiner and J. T. Herron, "Energetics of Gaseous Ions," J. Phys. Chem. Ref. Data, Supplement No. 1, Vo1.6, $1-783,1977$.

4. D. Sims, "Abstractor's Instructions", in preparation.

5. B. C. Duncan and D. Garvin, "Complete Clear Text Representation of Scientific Documents in Machine-Readable Form", NBS Tech. Note 820 (February 1974). 
- 13. APENDIX EOmposite and Red Snife uymbols Tatle - August 1976 Version. syribol Type Components Hame Ho.

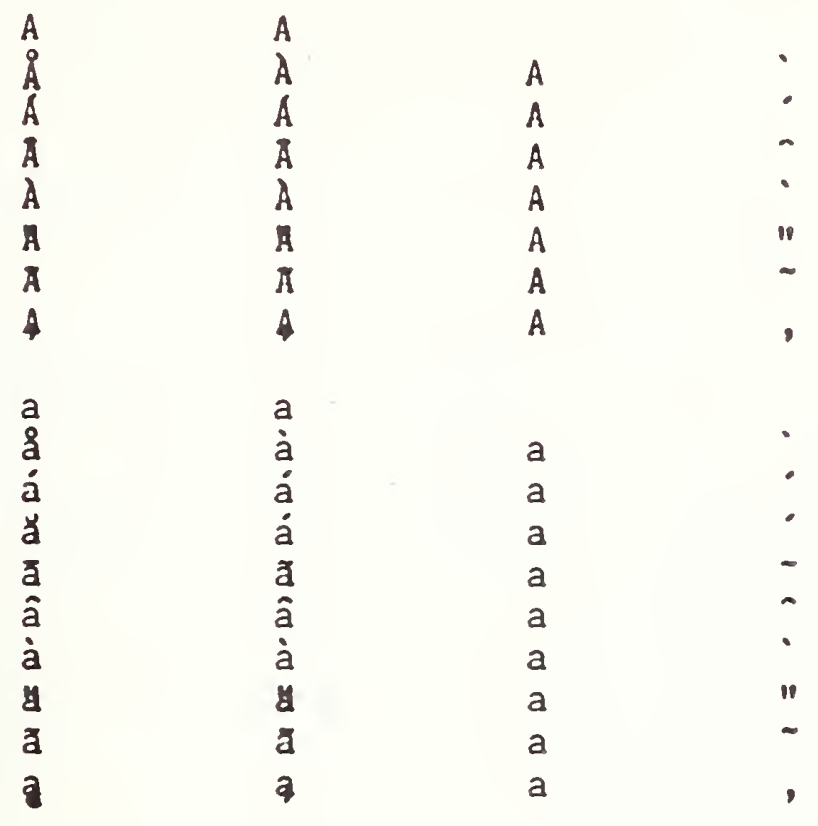

\section{A}

Angstrom

A acute

A circumflex

A Erave

A umlaut

A tilde

A cedilla

a

angstrom

a acute

a breve

a macron

a circumplex

a grave

a umlaut

a tilde

a hook

B

b

C

C acute

C breve

C macron

copyright

C cedilla

c

c acute

c breve

cent

c cedilla

D

d

E。

E Erave

E circumflex

E acute

E macron

E umlaut

E tilde

E cedilla

e

e acute

e ureve

e macron

e circumflex

: rrave
33

257

318

258

259

260

314

465

65

261

319

366

368

262

263

264

315

375

34

66

35

466

320

390

428

287

67

347

356

294

238

36

68

37

267

266

265

394

258

467

468

69

269

367

369

è 
HoS Composite and Red inirt. Gymbols Table - nugust 1976 Vers

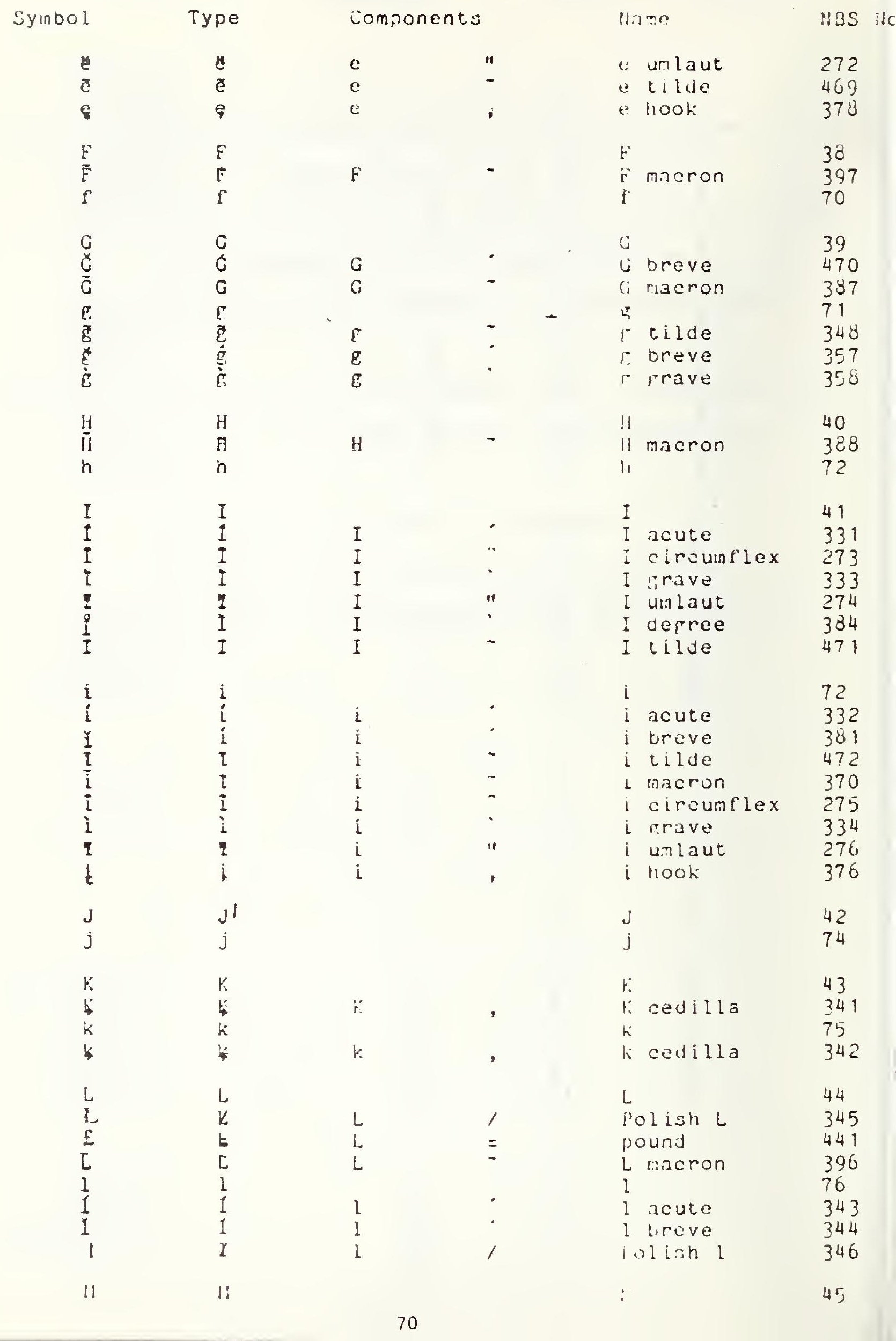


APPENDIX A (continued)

WES Composite and fied Snit' s\%nools Tatle - nuguat 1976 Verslon.

3ymool

กิ
11
1
0

$n$
$n$
$n$
$n$
$\bar{n}$
$\square$

0

0

0

0

0

0

0

0
0
0
0
0
0
0
0
0

P

p

Q

q

K.

(A)

$\dot{r}$

$\check{r}$

5

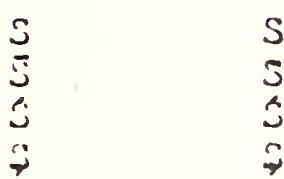

$\stackrel{3}{s}$

$\check{3}$

$T$
Type

m

m

it

ก

in

$n$
$n$
$\dot{n}$
$\dot{n}$
$n$

0

0

0

0

0

0

$\emptyset$

0
0
0
0
0
0
8
0
0

P

p

Q

i

R

$\dot{r}$

5

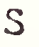

5

2

$\dot{s}$

$\dot{s}$
Comporrents

m

II

$n$
$n$
$n$
$n$
$n$

$n$
$n$
$n$
$n$
$n$

$n$
$n$
$n$
$n$
$n$

$n$
$n$
$n$
$n$
$n$

$n$
$n$
$n$
$n$
$n$

0
0
0
0
0
0

0
0
0
0
0
0
0
0

(n)

(n)

-

(n)

-

(

,

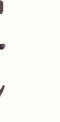

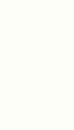


NBS Composite and lied Snift uymbols Taula - Aurust 1976 Vers

\begin{tabular}{|c|c|c|c|c|c|c|}
\hline Symbol & Type & $\mathrm{Co}$ & & & 1.28 & NL: \\
\hline 5 & 5 & $\tau$ & , & 七 & codilla & 364 \\
\hline$U$ & U & & & U & & 53 \\
\hline 0 & 0 & $U$ & - & U & tiLde & 475 \\
\hline 0 & ఠ & $U$ & $\cdot$ & U & acute & $33 \bar{y}$ \\
\hline 0 & 0 & $U$ & - & U & circuinfiex & 201 \\
\hline 0 & U & $U$ & $\cdot$ & $U$ & Prave & 282 \\
\hline U & $u$ & $U$ & $"$ & ن & $\Delta m l a u t$ & 233 \\
\hline$u$ & u & & & $u$ & & 35 \\
\hline 0 & a & $u$ & $\sim$ & $u$ & tilde & 476 \\
\hline$\dot{u}$ & $\dot{u}$ & $u$ & $\cdot$ & $山$ & acute & 340 \\
\hline $\bar{u}$ & ป & $u$ & - & u & macron & 372 \\
\hline 品 & $\bar{u}$ & $\mathrm{u}$ & $\cdot$ & $u$ & derree & 373 \\
\hline$\hat{u}$ & $\hat{u}$ & $u$ & 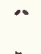 & $u$ & aircuinflex & 204 \\
\hline$\dot{u}$ & $\dot{u}$ & $u$ & • & $u$ & rrave & 235 \\
\hline$u$ & $u$ & $u$ & $"$ & u & morllaut & 236 \\
\hline 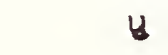 & 4 & $u$ & , & $u$ & hout: & 377 \\
\hline v & V & & & v & & 54 \\
\hline$v$ & $\mathrm{v}$ & & & $v$ & & 86 \\
\hline w & $W$ & & & i: & & 55 \\
\hline$w$ & w & & & : & & 87 \\
\hline$x$ & $\ddot{x}$ & & & $\therefore$ & & 30 \\
\hline$\overline{\mathrm{X}}$ & $\bar{X}$ & $x$ & - & $i$ & macron & 391 \\
\hline$x$ & $x$ & & & $x$ & & 8 \\
\hline$\hat{\bar{x}}$ & $\hat{x}$ & $x$ & - & $\hat{x}$ & macron & 3135 \\
\hline Y & $Y$ & & & $Y$ & & 57 \\
\hline y & $y$ & & & $y$ & & 33 \\
\hline$\dot{y}$ & $\dot{y}$ & $y$ & $\cdot$ & y & acute & 374 \\
\hline 2 & Z & & & $\ddot{L}$ & & 53 \\
\hline 2 & 2 & 2 & - & $\ddot{z}$ & acute & 477 \\
\hline 2 & 2 & 2 & $\cdot$ & & rrave & 478 \\
\hline 2 & $z$ & & & $\therefore$ & & no \\
\hline$z$ & $\dot{z}$ & 2 & • & & ree over $=$ & \\
\hline & & & & & $=210 t$ & 354 \\
\hline$\dot{z}$ & $\dot{z}$ & 2 & $\cdot$ & & acute & 355 \\
\hline$z$ & $\dot{z}$ & 2 & - & $\because$ & ureve & 305 \\
\hline
\end{tabular}


APPENDIX A (continued)

- Hes composite and lied sntre symbols iablo - Aurust 1976 version.

\begin{tabular}{|c|c|c|c|c|}
\hline Symbol & Type & Components & Hame & 115. \\
\hline$\alpha a$ & a & & alpha & 147 \\
\hline$\beta$ & b & & veta & 148 \\
\hline$\gamma$ & $r$ & & palina & 149 \\
\hline$\Gamma$ & 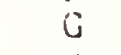 & & (รa)ไn & 130 \\
\hline$\delta$ & $d$ & & delta & 15,0 \\
\hline$\Delta$ & D & & Delta & 137 \\
\hline e & e & & epeilon & 151 \\
\hline$e^{\prime}$ & $\dot{e}$ & $e$ & epsilon acute & 383 \\
\hline 5 & $z$ & & aeta & 152 \\
\hline$\eta$ & $\mathrm{h}$ & & eta & 153 \\
\hline$\theta$ & $\theta$ & 0 & Trieta & 138 \\
\hline$\theta$ & a & & theta & 154 \\
\hline$\iota$ & $i$ & & iota & $1 \therefore 1$ \\
\hline$x$ & $k$ & & hisplia & 155 \\
\hline$\Lambda$ & L & & Lambat & 139 \\
\hline$\lambda$ & 1 & & lambia & 156 \\
\hline$\mu$ & $m$ & & $\ln u$ & 157 \\
\hline$v$ & $n$ & & nu & 158 \\
\hline$\circ$ & 0 & & ellipie & \\
\hline & & & or oriferon & 194 \\
\hline$\xi$ & j & & $x i$ & 15,9 \\
\hline$\Xi$ & J & & $x_{i}$ & 140 \\
\hline$\pi$ & $p$ & & $p i$ & 160 \\
\hline$\Pi$ & $\mathrm{P}$ & & $\mathrm{Pi}$ & $14 !$ \\
\hline$\Pi$ & is & & product & 116 \\
\hline p & $r$ & & $1 \cdot 110$ & 161 \\
\hline$\sigma$ & $s$ & & s. รุı. & 162 \\
\hline$\Sigma$ & $\dddot{j}$ & & sirma & 142 \\
\hline$\sum$ & C & & sum & 117 \\
\hline$r$ & $t$ & & tau & 163 \\
\hline$u$ & $u$ & & upition & 182 \\
\hline$r$ & U & & Upsilon & 143 \\
\hline$\phi$ & $\phi$ & 0 & fin: & 16,4 \\
\hline$\Phi$ & $\omega$ & 0 & $\operatorname{lni}$ & 144 \\
\hline$x$ & $x$ & & Chi & 165 \\
\hline$\downarrow$ & $y$ & & pii & 16,6 \\
\hline$\Psi$ & Y & & $\operatorname{lisi}$ & 145 \\
\hline$\omega$ & if & & onesa & 107 \\
\hline$\Omega$ & 6. & & 0rmora & 140 \\
\hline
\end{tabular}




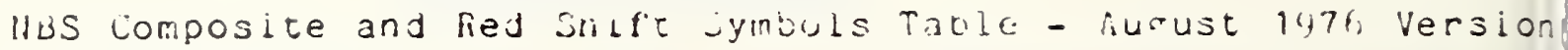

\begin{tabular}{|c|c|c|c|c|}
\hline Symool & Type & Corpontents & $11.37 e^{2}$ & IES \\
\hline$!$ & $!$ & & Exclametion & 1 \\
\hline$"$ & $"$ & & double prime & $\ddot{2}$ \\
\hline - & $\cdot$ & & prime, accent acute, & or \\
\hline 0 & & & apostropile & \\
\hline 。 & • & & accent rrave & 32 \\
\hline 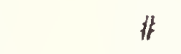 & \# & & number or scratch & 3 \\
\hline$\$$ & $\$$ & & dollar iorn & 4 \\
\hline$b$ & ib & & percent & 5 \\
\hline$\&$ & $\&$ & & arpersand & i \\
\hline ? & e & & commercial at & 64 \\
\hline( & ( & & lere parenthesis & $\delta$ \\
\hline$)$ & ) & & riplit maruchesis & 9 \\
\hline[ & {[} & & left braciet & 59 \\
\hline j & ] & & rirht uracrict & 0,1 \\
\hline 1 & $i$ & & left brace & 31 \\
\hline$\}$ & \} & & ripht urace & $7 j$ \\
\hline * & $*$ & & asterisk & 10 \\
\hline - & - & & period & 14 \\
\hline$:$ & : & & colon & 20 \\
\hline , & , & & comma & $1 \hat{c}$ \\
\hline ; & ; & & semicolon & 27 \\
\hline 1 & 1 & & slant/slash & 15 \\
\hline 1 & $i$ & & reverse slush & $\dot{6 C}$ \\
\hline 1 & $i$ & & verical uar & 92 \\
\hline$?$ & $?$ & & question riarri & 31 \\
\hline+ & + & & plus & 11 \\
\hline - & - & & : inus & 13 \\
\hline- & - & & hyphen & 101 \\
\hline$\longrightarrow$ & 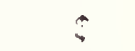 & & thict: das? & 100 \\
\hline$=$ & $=$ & & equal & 29 \\
\hline$<$ & $<$ & & less than & 20 \\
\hline$>$ & $>$ & & Eroater than & 30 \\
\hline- & - & & tilda & 94 \\
\hline- & - & & eircuritlex & $0 \hat{\imath}$ \\
\hline - & - & & underl the & 63 \\
\hline$x$ & $x$ & & pultiplicil by & 119 \\
\hline$\Gamma$ & 11 & & del & 118 \\
\hline$\partial$ & is & & difrerential & 134 \\
\hline 0 & $\dot{A}$ & & diamunes & 171 \\
\hline 口 & $\|$ & & lozenre & 130 \\
\hline$\Pi$ & is & & prouduct & 116 \\
\hline$\Sigma$ & $\ddot{\imath}$ & & SU17 & 117 \\
\hline o & 0 & & ollipso & 194 \\
\hline & I & & interal & 133 \\
\hline$\delta^{J}$ & 2 & ! & conbour interral & 401 \\
\hline $\mathcal{S} V$ & * & & siuilri ruot & 135 \\
\hline$\div+$ & + & - & Hivingid ly & 297 \\
\hline+ & + & & $: 111:$ & 11 \\
\hline \pm & $t$ & + & Wius ,." 17 inus; & 31 \\
\hline$F$ & $\mp$ & + & $: a 1 i, \quad \because, 11 \ldots$ & $; \because 2$ \\
\hline & & 74 & & \\
\hline
\end{tabular}


WBS Composite and Red Inift symbols Table - Nugust 1976 Version.

Symbol

3
2
3
1
1

$\propto$

$\infty$

$\sim$

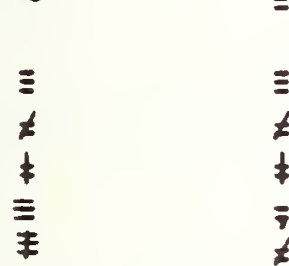

$\forall$

乞

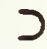

y

p

$\frac{3}{5}$

$\cdot$

II

$f$

t

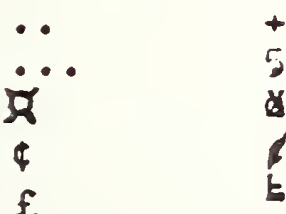

(a)

(c)

R

C

$\mathrm{v}$

$\equiv$
$\neq$
$\ddagger$
$\vdots$

$i$
Type

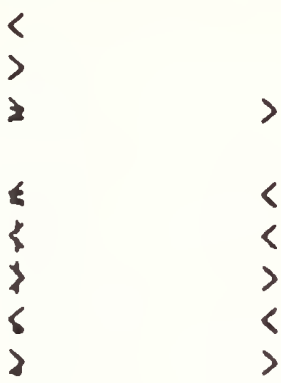

v

$=$

$\because 1$

$=1$
$=1$

Components

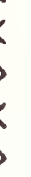

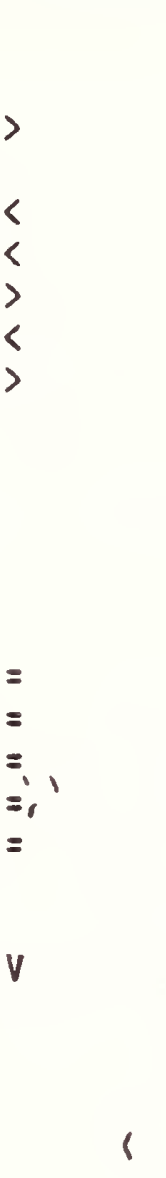

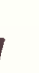

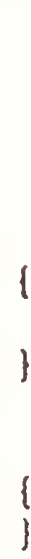

\}

$\dot{x}$

c

$\oint$

!r

c $\sim$

is confruent

not equal

not equal

is identical

not identically

equal

lofical not

lorical for all

is a subset

intersection

of two sets

contained as

a subset

union of two sets

is not a subset of

105

402

is not contained as a subset

there cxists

is an element of

such that

reversible reaction

center dot

pararraph

dagger

darrer

double darfer

two dot leader

tirree dot leader

currency

cent

pound

403

113

404

405

183

175

189

123

123

124

180

393

442

294

441 


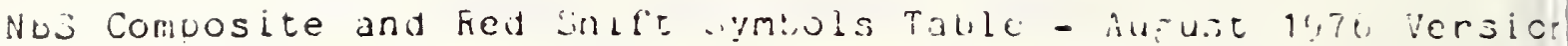

\begin{tabular}{|c|c|c|c|c|}
\hline jymool & Type & Coriponents & $\because \because: 1: 1+1$ & $: 150$ \\
\hline , & $\cdot$ & & aeseri! loute & 7 \\
\hline " & ‘ & & acceril, riave & 32 \\
\hline$"$ & $"$ & & iscoent unlaut & $?$ \\
\hline 6 & $\vdots$ & . & open (astile & 145,0 \\
\hline , & $\therefore$ & $\cdot$ & 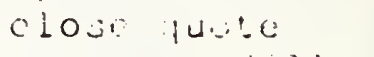 & 45,1 \\
\hline : & ! & & acoent (milila & $1 \bar{c}$ \\
\hline & & & derses & 122 \\
\hline - & $\sim$ & & $1.10 \mathrm{cros}$ & 190 \\
\hline & $\tau$ & & bréve. & 174 \\
\hline - & - & & $c \mid l(1)$ & 74 \\
\hline - & - & & circull: 1 lros: & $i, z$ \\
\hline- & - & & unwerlins: & $u=$ \\
\hline $\bar{u}$ & 0 & 0 & zero !n: & 320 \\
\hline$\overline{1}$ & 7 & 1 & one liacersu & $3<1$ \\
\hline$\leq$ & 2 & $z$ & two milerun & 320 \\
\hline$\frac{2}{3}$ & 3 & 3 & three macron & $3<3$ \\
\hline$\overline{4}$ & 4 & 4 & lour macrun & 324 \\
\hline$\overline{1}$ & 5 & 5 & live macros: & 325 \\
\hline 6 & 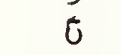 & 6 & 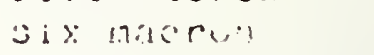 & $\therefore i$ \\
\hline$\overline{7}$ & 7 & 7 & Ecusin aror: & $3: ?$ \\
\hline$i$ & 8 & 8 & eipht riscron & $? 20$ \\
\hline$\overline{5}$ & 3 & is & nane & $\because 1$ \\
\hline $1 / 2$ & 2 & 1 & une & 453 \\
\hline$\pi 2$ & $\bar{z}$ & $\hat{2}$ & tiar val: hal $1 t^{\circ}$ & 492 \\
\hline $1 / 3$ & 3 & 1 & one thira & 100 \\
\hline $2 / 3$ & $z$ & $\ddot{c}$ & two ethir. & w? \\
\hline $1 / 4$ & 4 & 1 & one tourt! & 40,4 \\
\hline $3 / 4$ & 3 & 3 & three rourtise & 45 \\
\hline $1 / 6$ & 0 & 1 & one sixt:l & $46 c^{\circ}$ \\
\hline $5 / 6$ & 6 & 5 & tlivis $\equiv t$ thls & 40.3 \\
\hline $1 / 8$ & 8 & 1 & one pirpita & 450 \\
\hline $3 / 8$ & 3 & 3 & thre: $=1,-n t ! 1: 3$ & 1539 \\
\hline $5 / 0$ & 8 & 5 & five: 1. iri.cens & $4(10)$ \\
\hline $7 / 8$ & 8 & 7 & sreveril uirohths & $4 i 1$ \\
\hline
\end{tabular}


HUS Composite and Red Silir zymbols iable = Aüust 1976 Version. "

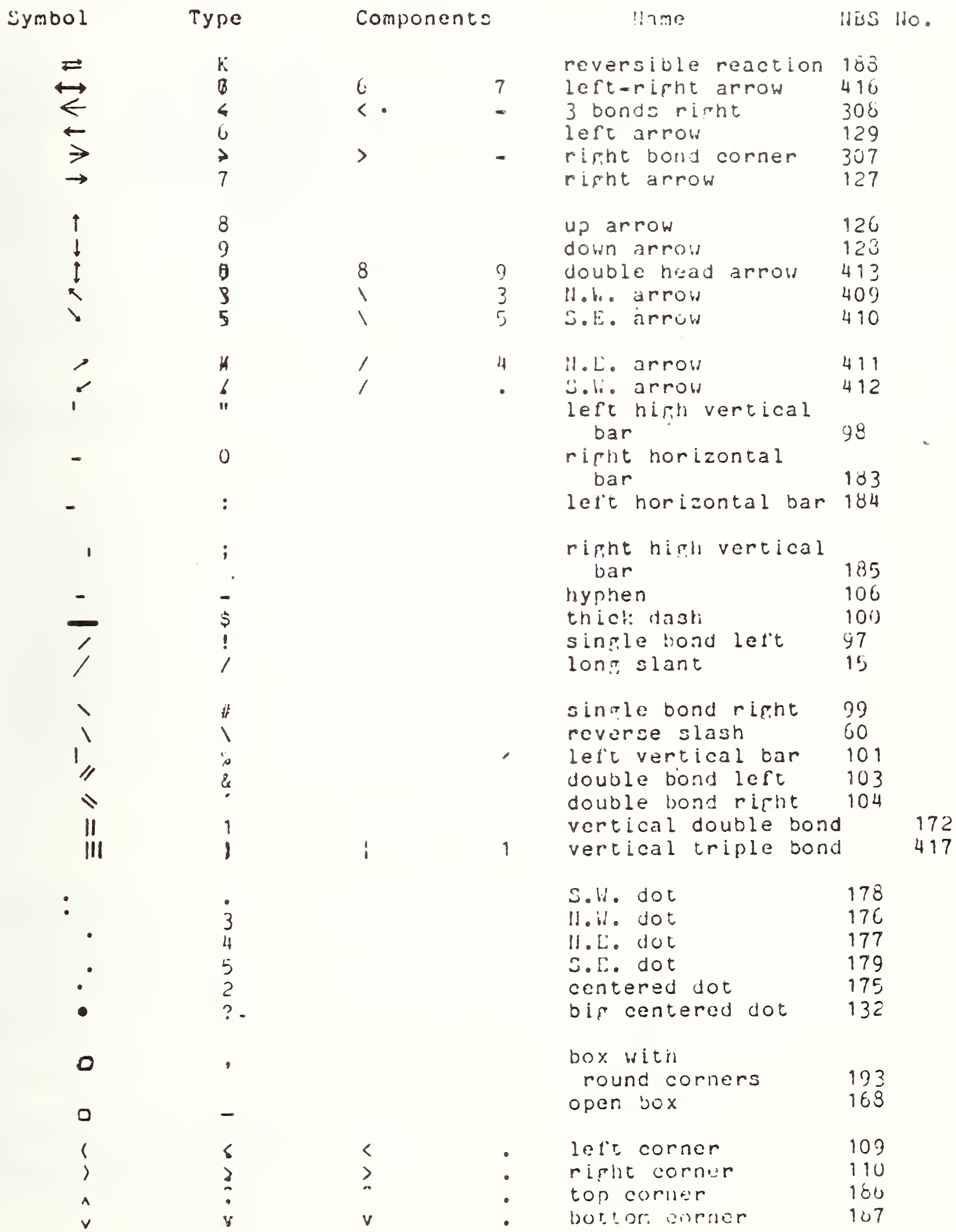


Wis Composte and Red Shift Symbols Table - August 1976 Version.

Symbol

Type

Components

Name

IIBS $1 \%$.

3
2
3
9
3
8
$?$
3
$?$.

1
2
3
4
5
6
7
8
9

$?$
$?$
$?$
$?$
$?$
$?$
$?$

mystery no. 1

481

mystery no. 2

482

mystery no. 3

483

mystery no. 4

484

mystery no. 5

485

mystery no. 6

486

inystery no. 7

487

488

mystery no. 8

$4 \div 0$ 
NDS.IIAA IREV 7.7J\}

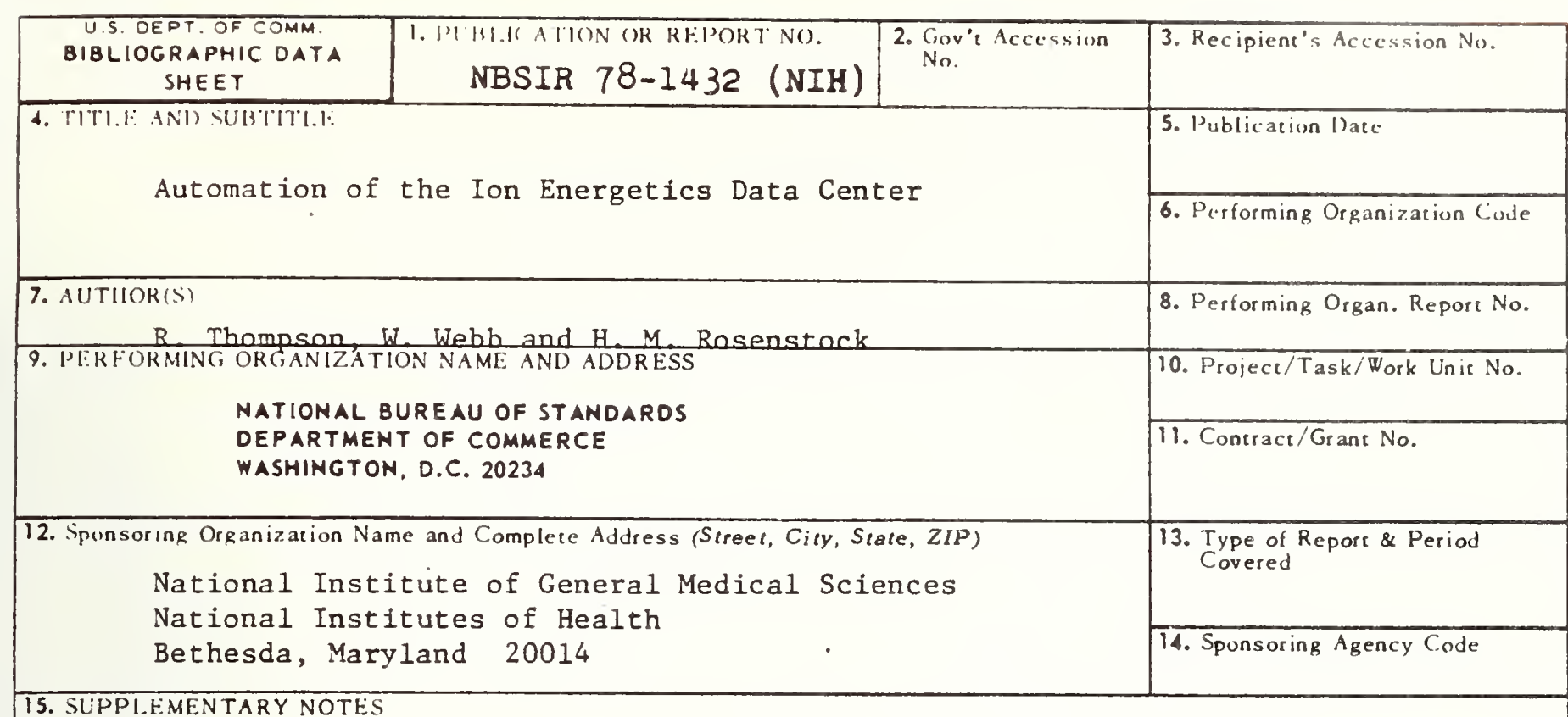

15. SUPPI.FMENTARY NOTES

16. ABSTRAC:T (A 200-word or less factual summary of most significant in formation. If document includes a significant biblingraphy or literature survey, mention it here.)

The Ion Energetics Data Center is engaged in the compilation, evaluation and dissemination of experimental information on gaseous ion energetics. Outputs include bibliographic and tabular information on ionization potentials, appearance potentials, electron affinities and heats of formation of gaseous positive and negative ions. The operation of the data center is discussed. This operation has recently been automated by the development of a set of computer programs, called IONPACK, which minimize the manual effort required for the numerous file manipulations and editing steps necessary to produce the data center output. The functions of the programs are outlined and the associated operating procedures are described in detall. Full documentation of the programs is presented in a separate report.

17. KFY WORI)S (six to twelve entries; alphabetical order; capitalize only the first letter of the first key word unless a proper name; separated by semicolons)

Abstract; appearance potential; archival tape; computer program; data base; data base management; empirical molecular formula; GPSDC; 1on energetics; ionization potential
18. AVALABILITY
[. Unimited

[.] For Official Distribution. Do Not Release to NTIS

[] Order From Sup. of Doc., U.S. Government Printing Office Washington, D.C. 20402 , SD Car. No. C: 3

\begin{tabular}{|c|c|}
\hline $\begin{array}{l}\text { 19. SECURITY CLASS } \\
\text { (THIS REPURT) } \\
\text { UNCL ASSIFIED }\end{array}$ & $\begin{array}{c}\text { 21. NO. OF PAGES } \\
81\end{array}$ \\
\hline $\begin{array}{l}\text { 20. SECURITY CLASS } \\
\text { (THISPAGE) } \\
\text { UNCLASSIFIED }\end{array}$ & $\begin{array}{l}\text { 22. Price } \\
\$ 6.00\end{array}$ \\
\hline
\end{tabular}

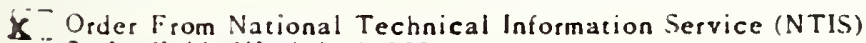
Springfield, Virginia 2215 I 
$6 \div 34$ 

MOORT

BOOA BINDIN

JUNE Bo 
